\title{
Déficit de acesso a serviços de saneamento ambiental: evidências de uma Curva Ambiental de Kuznets para o caso dos municípios brasileiros?
}

\author{
Carlos César Santejo Saiani ** \\ Rudinei Toneto Junior \\ Juscelino Antonio Dourado ${ }^{* * * *}$
}

\begin{abstract}
Resumo
O presente estudo avaliou a existência de uma Curva Ambiental de Kuznets (CAK) para o caso dos déficits municipais de acesso a serviços de saneamento ambiental, que podem ser considerados como medidas indiretas de degradação ambiental. Os resultados obtidos sinalizam, de uma maneira geral, a existência de uma relação entre os déficits de acesso e o desenvolvimento econômico no formato de um "N" e não no tradicional formato de um "U invertido" da CAK. Portanto, para o caso específico dos serviços de saneamento ambiental nos municípios brasileiros, a hipótese de que o desenvolvimento econômico seria a melhor solução para a preservação ambiental não é verdadeira, uma vez que, ao longo do tempo, o desenvolvimento econômico voltaria a gerar degradação ambiental.
\end{abstract}

Palavras-chave: Saneamento ambiental; Curva Ambiental de Kuznets; Painel de dados.

\begin{abstract}
Absence of access to the environmental sanitation services: evidences of an environmental Kuznets' curve in Brazilian's cities?

The present study evaluated the existence of an Environmental Kuznets' Curve (EKC) in the case of the absence of access to environmental sanitation services, which can be considered as an indirect measure of environmental degradation in Brazilian cities. The results show that the actual relation between access deficit of sanitation services and economic development is in an " $N$ " shape instead of the traditional "inverted-U" from the EKC. Therefore, for the specific case of the services of environmental sanitation in Brazilian cities, the hypothesis that sustains the economic development as the best solution for environmental preservation is not verifiable, as, over time, the economic development would generate again environmental degradation.
\end{abstract}

Keywords: Environmental sanitation; Environmental Kuznets Curve; Data panel.

JEL R500, R560, R580.

* Trabalho recebido em 14 de dezembro de 2010 e aprovado em 18 de março de 2012.

** Professor Doutor do Instituto de Economia da Universidade Federal de Uberlândia (IE-UFU), Uberlândia, MG, Brasil. E-mail: ssaiani@yahoo.com.br, ssaiani@ie.ufu.br.

*** Professor Titular do Departamento de Economia da Faculdade de Economia, Administração e Contabilidade de Ribeirão Preto da Universidade de São Paulo (FEARP-USP), Ribeirão Preto, SP, Brasil. E-mail: rtoneto@usp.br.

*** Graduado em Gestão Ambiental pela Escola Superior de Agricultura Luiz de Queiroz da Universidade de São Paulo (ESALQ-USP). Diretor do Instituto Estre de Responsabilidade Socioambiental, São Paulo, SP, Brasil. E-mail: dourado@terra.com.br. 


\section{Introdução}

O saneamento ambiental abrange os serviços de abastecimento de água, de esgotamento sanitário (coleta e tratamento), de manejo de resíduos sólidos (lixos) urbanos (coleta e disposição) e de águas pluviais urbanas. Esses serviços podem ser considerados como essenciais, uma vez que geram externalidades sobre o meio ambiente, a saúde pública e, consequentemente, sobre o desenvolvimento econômico sustentável.

Condições inadequadas no setor podem causar contaminação dos mananciais, dos cursos de água e dos solos, assoreamento dos rios e inundações, contribuindo para a formação de ambientes propícios à proliferação de agentes transmissores de doenças. Algumas dessas doenças são as principais causadoras de mortalidade infantil ${ }^{1}$. No caso dos adultos, as doenças podem debilitar os trabalhadores e até afastá-los do trabalho (morbidade), reduzindo a produtividade e a produção, que também é afetada pelos impactos sobre o meio ambiente ${ }^{2}$.

Apesar da importância dos serviços, existe um sério déficit de acesso a estes, que se distribui "de forma desigual pelo país" (Barat, 1998, p. 145). Alguns estudos mostram que diferenças de preferências e de capacidade de pagamento dos cidadãos, assim como de custos e de motivações dos governantes, influenciam o acesso.

Conforme defendem Shafik e Bandyopadhyay (1992), o déficit de acesso aos serviços de saneamento pode ser considerado como uma medida indireta de degradação ambiental, uma vez que a ausência de condições adequadas no setor gera externalidades negativas sobre o meio ambiente. Assim, pode-se questionar se esse déficit de acesso apresenta uma relação de longo prazo com o desenvolvimento econômico semelhante a outras medidas de degradação caracterizada pela existência da chamada Curva Ambiental de Kuznets (CAK).

A CAK, inicialmente observada por Grossman e Krueger (1991), é um importante tema da literatura sobre economia do meio ambiente e desenvolvimento sustentável. Trata-se da hipótese, corroborada em diversos estudos, de que existiria uma relação no formato de um "U invertido" entre indicadores de degradação ambiental e desenvolvimento econômico. Ou seja, a degradação aumentaria em estágios iniciais de desenvolvimento e passaria a diminuir quando certo nível fosse alcançado. Estudos mais recentes defendem que essa relação, para alguns indicadores, não se sustentaria no longo prazo, de modo que a degradação voltaria

(1) Diversos estudos encontraram evidências do impacto do saneamento ambiental sobre o óbito de crianças, inclusive para o caso brasileiro. Ver, por exemplo, Mendonça e Motta (2005).

(2) De acordo com Moreira (1996), estima-se que $80 \%$ das doenças e $65 \%$ das internações hospitalares no Brasil estejam correlacionadas ao setor. 
a aumentar em níveis mais avançados de desenvolvimento. Assim, a relação teria, na verdade, o formato de um "N".

Nesse contexto, o objetivo do presente estudo é avaliar a existência da CAK para o caso do déficit municipal de acesso a serviços de saneamento ambiental; ou seja, averiguar se o desenvolvimento econômico leva, inicialmente, a um aumento do déficit de acesso aos serviços. Contudo, a partir de certo estágio, o próprio desenvolvimento acaba resultando em um menor déficit. Além disso, pretende-se averiguar se essa redução se sustenta em estágios mais avançados de desenvolvimento. É importante destacar que se trata de um estudo exploratório que avaliará a existência ou não da CAK para o caso dos serviços de saneamento ambiental e, por mais que esta não seja apresentada apenas como um fato estilizado, explicações mais aprofundadas ficarão como motivação para trabalhos futuros.

Para atingir o objetivo proposto, são realizadas estimações pelo método de efeitos fixos para um painel de municípios brasileiros com dados referentes a 1991 e 2000, coletados junto aos Censos Demográficos dos respectivos anos, realizados pelo IBGE. Devido à disponibilidade de informações, são considerados três serviços: (i) coleta de lixo; (ii) coleta de esgoto e (iii) abastecimento de água. A análise dos três serviços possibilita a obtenção de evidências mais robustas, pois permite averiguar a existência ou não de uma tendência comum das políticas públicas voltadas ao saneamento ambiental. Para cada um dos serviços, são construídos três indicadores municipais de déficit, considerando a proporção total de domicílios sem acesso, a proporção de domicílios mais pobres sem acesso e a proporção de domicílios mais ricos sem acesso. A análise de três indicadores também é uma forma de obter evidências mais robustas da existência ou não da CAK, uma vez que alguns estudos mostram que o acesso é influenciado pela renda domiciliar.

Situações inadequadas dos serviços geram externalidades negativas sobre o meio ambiente independentemente da localização das moradias. Por isso, os indicadores de acesso são calculados com informações dos domicílios urbanos e rurais. Contudo, nas áreas urbanas, a concentração populacional pode resultar em economias de escala e de densidade, assim como em uma maior pressão da população por serviços mais adequados. Além disso, há diferenciais de rendimento entre os trabalhadores urbanos e rurais. Esses fatores podem levar a um acesso mais amplo em municípios com maior urbanização, independentemente do desenvolvimento econômico. Para lidar com essa possibilidade, são adotadas duas estratégias: (i) utilização da taxa de urbanização dos municípios como controle nas estimações, e (ii), como teste de robustez, estimações com indicadores de déficit de acesso urbano.

Outra estratégia utilizada para testar a robustez dos resultados consiste na realização de estimações, desconsiderando os municípios que, no período, 
concederam os serviços à iniciativa privada. Dessa forma, são desconsiderados potenciais efeitos da desestatização sobre os resultados. As informações sobre o tipo de prestador em cada município são disponibilizadas pelo Ministério das Cidades e pela Associação Brasileira das Concessionárias Privadas dos Serviços Públicos de Água e Esgoto (ABCON).

Adicionalmente, são realizadas estimações desagregando a amostra de municípios em regiões geográficas (Norte, Nordeste, Centro-Oeste, Sul e Sudeste), o que possibilita analisar se, dentro destas, são observadas relações do tipo da CAK. Tal desagregação permite avaliar, ainda, se os resultados encontrados para o Brasil refletem a relação entre a degradação ambiental e o desenvolvimento econômico ou apenas diferenças regionais entre os municípios. Nesse sentido, também são utilizadas algumas covariadas para controlar possíveis determinantes do acesso, garantindo maior confiabilidade à evidência estimada para a relação entre o déficit de acesso a serviços de saneamento ambiental e o desenvolvimento econômico.

$\mathrm{O}$ artigo possui, além desta introdução, mais cinco seções. Na primeira seção, é realizada uma revisão da literatura sobre a CAK, na qual são apresentadas as possíveis justificativas para a existência da relação. $\mathrm{Na}$ segunda seção, os indicadores de déficit municipal de acesso aos serviços de saneamento ambiental construídos neste estudo são apresentados e, por meio destes e de uma breve revisão da literatura, é realizada uma caracterização do problema. Na primeira e segunda seções, também são justificadas as principais variáveis de controle utilizadas nos testes econométricos, que têm suas estratégias de estimação apresentadas na terceira seção. Os resultados são analisados na quarta seção, e após as considerações finais.

\section{Curva Ambiental de Kuznets: possíveis justificativas e formatos}

De acordo com Beckerman (1992), o desenvolvimento econômico causa, inicialmente, degradação ambiental. Contudo, ao longo do tempo, é a melhor forma - ou talvez a única - de se alcançar um meio ambiente mais preservado. Essa afirmação se baseia na hipótese de que, nos primeiros estágios do desenvolvimento, a degradação aumentaria, mas diminuiria em estágios mais avançados. Ou seja, existiria uma relação não linear no formato de um "U invertido", não necessariamente simétrico, entre o desenvolvimento econômico e a degradação ambiental. Em função do formato semelhante ao da Curva de Kuznets $^{3}$, essa relação ficou conhecida como Curva Ambiental de Kuznets (CAK).

(3) Trata-se da provável relação, também no formato de um "U invertido", entre a desigualdade de renda e o desenvolvimento econômico, ou seja, a desigualdade aumentaria nos estágios iniciais de desenvolvimento e passaria a diminuir em estágios mais avançados (Kuznets, 1955). Deutsch e Silber (2000) fazem uma survey dos trabalhos que apresentaram possíveis explicações e evidências empíricas dessa relação. 
O trabalho de Grossman e Krueger (1991), que avaliou a relação entre poluição do ar e renda per capita em áreas urbanas de diversos países, considerando informações referentes às décadas de 1970 e 1980, foi o primeiro a encontrar evidências da CAK. A partir desse resultado, vários estudos testaram a validade da hipótese, utilizando diversos métodos (paramétricos ou não paramétricos), amostras e períodos distintos, inclusive para o caso de estados e municípios brasileiros, assim como diferentes medidas de degradação ambiental $^{4}$. Alguns trabalhos apresentaram a CAK apenas como um fato estilizado, enquanto outros tentaram justificá-la. A partir da análise destes últimos, pode-se dizer que aspectos econômicos, políticos e institucionais se complementam na explicação da relação.

Arrow et al. (1995), por exemplo, atribuem o aumento da degradação ambiental no início do desenvolvimento econômico à transição de uma economia agrícola para uma economia industrial, que utiliza mais intensivamente os recursos naturais e emite mais poluentes ${ }^{5}$. Nesse período, de acordo com Yandle et al. (2002), os agentes estão mais preocupados em aumentar a produção e, consequentemente, a renda, negligenciando os impactos ambientais - em parte, por ignorância. A expansão do consumo, decorrente do crescimento da renda, pressiona ainda mais o meio ambiente, uma vez que aumenta a geração de resíduos sólidos e a utilização de bens que emitem poluentes (Arraes et al., 2006).

Andreoni e Levinson (2001) explicam a CAK por meio da hipótese de existência de economias de escala de poluição. Nos estágios iniciais do desenvolvimento, as escalas de produção são pequenas, de modo que seria muito custoso adotar técnicas de controle de poluição. À medida que a economia se desenvolve, as escalas de produção elevam-se, o que reduziria o custo e, consequentemente, aumentaria a adoção de tais técnicas. Os próprios autores ressaltam que tal explicação só é válida para alguns tipos de medidas de degradação.

Segundo Stern (2004), ao longo do tempo, há uma tendência de elevação da produção de bens e serviços com menores impactos negativos sobre o meio ambiente em função do aumento da expectativa de vida e do nível educacional da população - consequências diretas do desenvolvimento. Esses fatores fazem com que os indivíduos valorizem mais a qualidade do ar, do solo e da água, demandando produtos que degradam menos o meio ambiente e, consequentemente,

(4) Os principais resultados internacionais são apresentados na survey realizada por Stern (2004); já resultados para o caso de localidades brasileiras podem ser avaliados em Fonseca e Ribeiro (2005), Santos et al. (2008) e Sousa et al. (2008).

(5) As atividades agrícolas também passam a degradar mais o meio ambiente em função da adoção de práticas modernas de produção, como o uso de agrotóxicos (Sousa et al., 2008). 
incentivando as empresas a buscarem inovações nesse sentido, ou seja, a qualidade ambiental possuiria uma elasticidade-renda positiva (Selden; Song, 1994).

A maior conscientização ambiental também se reflete no aumento da demanda por políticas públicas e instituições que garantam uma maior preservação. Tais medidas são efetivamente adotadas se os indivíduos conseguirem influenciar as decisões dos governantes, considerando que estes sejam motivados pela maximização de oportunidades eleitorais. Duas decorrências diretas do desenvolvimento econômico contribuem para isso ${ }^{6}$.

A primeira decorrência é a elevação da concentração populacional em áreas urbanas, que, ao reduzir a distância entre os indivíduos, aumenta a possibilidade de se organizarem e, consequentemente, exercerem maior influência política para o atendimento de suas preferências. Selden e Song (1994) defendem esse argumento. Os autores utilizaram, em suas estimações, a densidade demográfica como o indicador de concentração populacional, encontrando evidências de que esta se relaciona negativamente com a degradação ambiental. Nessa mesma linha de raciocínio, Templeton e Scherr (1999) apontam que o aumento populacional pode causar, inicialmente, pressão sobre o meio ambiente, mas, ao longo do tempo, induziria um aumento da preservação.

Outra decorrência é o aumento da parcela da população com participação política - considerando a hipótese de que existiria uma relação positiva entre esta e o nível educacional da população, que se elevaria ao longo do desenvolvimento econômico (Gradstein; Justman, 1999). Segundo Torras e Boyce (1998), uma distribuição mais equitativa do poder político resultaria em um aumento da preservação ambiental, uma vez que aqueles que sofrem relativamente mais com o custo da degradação poderiam pressionar a adoção de medidas preservacionistas. Os autores consideram como determinantes da distribuição do poder político, além do nível educacional, a heterogeneidade étnica e a desigualdade de renda.

Por último, é importante destacar que diversos trabalhos encontraram evidências de formatos diferentes do "U invertido" para a relação entre o desenvolvimento econômico e algumas medidas de degradação ambiental. Jones e Manuelli (1998), por exemplo, mostraram que, para alguns casos, essa relação assumiria o formato de um "N". Ou seja, a degradação ambiental passaria a aumentar em níveis mais elevados de desenvolvimento. Para os autores, esse formato decorreria da capacidade de as instituições ambientais internalizarem as externalidades negativas geradas pela atividade econômica.

(6) Segundo Arrow et al. (1995) e Dinda (2004), a expansão do comércio internacional e a globalização são outros fatores que contribuem para a adoção de tais medidas, uma vez que os governantes dos países em desenvolvimento também podem sofrer pressões dos países desenvolvidos. 


\section{Saneamento ambiental no Brasil: caracterização do déficit de acesso}

Nas estimações realizadas no presente estudo, são utilizados indicadores municipais calculados a partir de informações disponibilizadas pelos Censos Demográficos de 1991 e 2000, realizados pelo IBGE. A seguir, alguns dos indicadores são apresentados e, por meio destes e baseando-se em uma breve revisão da literatura, é realizada uma análise descritiva com o objetivo de caracterizar e apontar possíveis determinantes do acesso aos serviços de saneamento ambiental no Brasil.

São analisados três serviços: (i) coleta de lixo; (ii) coleta de esgoto e (iii) abastecimento de água e calculados, para cada município e ano, três indicadores de déficit de acesso:

- déficit total: proporção total de domicílios sem acesso ao serviço ${ }^{7}$;

- déficit no $1^{\circ}$ quintil (mais pobres): proporção de domicílios no primeiro quintil de renda domiciliar per capita sem acesso ao serviço

- déficit no $5^{\circ}$ quintil (mais ricos): proporção de domicílios no quinto quintil de renda domiciliar per capita sem acesso ao serviço ${ }^{8}$.

A literatura especializada aponta a rede geral como o modo ideal de abastecimento de água e de esgotamento sanitário. No caso do destino do lixo, o modo ideal é a coleta por serviço de limpeza, diretamente ou por meio de caçambas ${ }^{9}$. Essas formas são apontadas como ideais em função do menor risco de contaminação do ar, das águas e dos solos, ou seja, dos menores impactos potenciais sobre o meio ambiente e sobre a saúde pública. Formas alternativas aumentam o risco de contaminação e, consequentemente, de impactos sociais negativos, pois, em geral, são soluções individuais que não levam em conta as

(7) Na verdade, nos Censos Demográficos, só é possível obter essas informações para os domicílios particulares permanentes, que são moradias construídas para servir exclusivamente como habitação. Há outras espécies de domicílios com informações não disponibilizadas: (i) particulares provisórios - moradias localizadas em unidades não residenciais (lojas, fábricas, etc.), com dependências não destinadas exclusivamente à moradia e (ii) domicílios coletivos (hotéis, pensões, presídios, cadeias, penitenciárias, quartéis, postos militares, escolas, asilos, orfanatos, conventos, mosteiros, hospitais, clínicas com internações, alojamentos de trabalhadores, motéis, campings, etc.).

(8) Em cada município e em cada ano, os domicílios foram ranqueados em função da renda domiciliar per capita, sendo calculadas as proporções de domicílios com acesso no primeiro quintil de renda (mais pobres) e no quinto quintil de renda (mais ricos).

(9) O IBGE, na realização dos Censos Demográficos, considera que o domicílio possui abastecimento de água por rede geral quando o terreno ou a propriedade onde está localizado se interligam a um sistema geral de abastecimento. No caso do esgoto, considera que o domicílio possui rede geral quando a canalização das águas servidas e dos dejetos provenientes do banheiro ou do sanitário é ligada a um sistema de coleta que conduza a um desaguadouro geral da área, região ou município, mesmo que o sistema não disponha de estação de tratamento da matéria esgotada. Já no caso do lixo, considera que o domicílio possui coleta por serviço de limpeza quando: (i) o lixo produzido no domicílio é coletado diretamente por serviço de empresa pública ou privada; ou (ii) o lixo produzido no domicílio é depositado em caçambas, tanques ou depósitos, fora do domicílio, para depois ser coletado por serviço de empresa pública ou privada. 
externalidades negativas que podem ser geradas ${ }^{10}$. Diante desses fatos, optou-se por considerar como ausência de acesso domiciliar quando o abastecimento de água e o esgotamento sanitário não são realizados por rede geral, assim como quando o lixo produzido não é coletado por serviço de limpeza. Dessa forma, os déficits de acesso aos serviços podem ser entendidos como medidas indiretas de degradação ambiental, uma vez que causariam esse problema ${ }^{11}$.

A Figura 1 mostra a distribuição dos déficits de acesso dos municípios brasileiros em 1991 e 2000. Complementando a figura, logo abaixo dela, é apresentada uma tabela com os indicadores municipais médios nos dois anos considerados. O primeiro aspecto a ser destacado a partir da análise dessas informações é que o abastecimento de água era o serviço que apresentava, no total, nas duas faixas de renda domiciliar e nos dois anos, a melhor situação - de uma maneira geral, menores déficits médios e menores concentrações de municípios com ausência de acesso em todos os domicílios. Nesse sentido, a coleta de lixo apresentava uma posição intermediária e a coleta de esgoto indicava os maiores problemas de consolidação da cobertura. Nos três serviços, os déficits médios e as concentrações de municípios com elevados indicadores diminuíram no período.

De acordo com o BNDES (1998), a melhor situação do abastecimento de água decorre, em grande parte, da alocação dos investimentos públicos ao longo do tempo, que teriam privilegiado o serviço em função da maior rentabilidade e da visibilidade política superior e mais imediata, uma vez que os próprios cidadãos podem ter maior preferência por água encanada. Uma evidência nesse sentido foi constatada no "Exame da Participação do Setor Privado na Provisão dos Serviços de Abastecimento de Água e de Esgotamento Sanitário no Brasil” realizado pelo Ministério das Cidades. Ao entrevistar diversas famílias que passaram a ter acesso e a ser cobradas pelos serviços após um processo de desestatização, $27 \%$ dos entrevistados disseram que preferiam estar conectados somente ao abastecimento de água e apenas $2 \%$ responderam que preferiam estar conectados somente à coleta de esgoto - $64,8 \%$ preferiam os dois serviços; $3,3 \%$ nenhum deles e 2,9\% não souberam responder ou não quiseram opinar.

Na Figura 1, também é possível observar, nos três serviços, uma maior concentração de municípios com menores indicadores no $5^{\circ}$ quintil e que os déficits médios nesse quintil são menores do que no $1^{\circ}$ quintil. Além disso, na

(10) As principais formas alternativas de abastecimento de água são poços ou nascentes localizados ou não no terreno ou na propriedade do domicílio. Já as principais formas alternativas de esgotamento sanitário são fossas sépticas ou rudimentares, valas a céu aberto, rios, lagos ou mares. No caso do lixo, se não houver coleta, este é geralmente queimado, enterrado ou jogado em terrenos baldios, logradouros, rios, lagos ou mares.

(11) Indicadores de déficit de acesso a serviços de saneamento ambiental também foram usados como medidas de degradação ambiental por Shafik e Bandyopadhyay (1992) e Sousa et al. (2008). 
Déficit de acesso a serviços de saneamento ambiental: evidências de uma Curva Ambiental de Kuznets...

média, as ausências de acesso aos serviços reduziram-se mais, entre 1991 e 2000, nos domicílios mais ricos.

Figura 1

Brasil: indicadores municipais de déficit de acesso (distribuição e média), 1991 e 2000

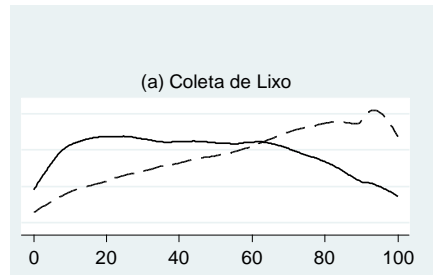

(1) Déficit Total

(b) Coleta de Esgoto

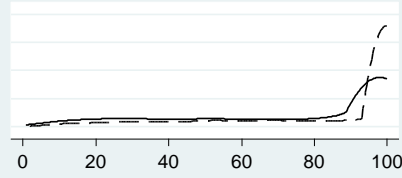

(c) Abastecimento de Água

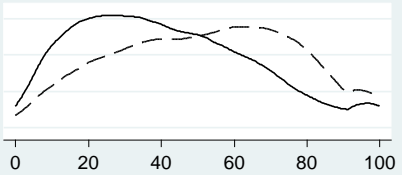

(2) Déficit no $1^{\circ}$ Quintil

(d) Coleta de Lixo

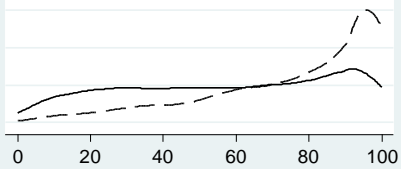

(e) Coleta de Esgoto

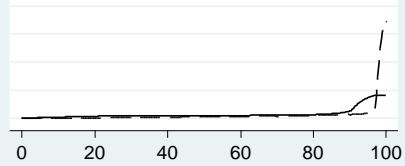

(3) Déficit no $5^{\circ}$ Quintil

(g) Coleta de Lixo

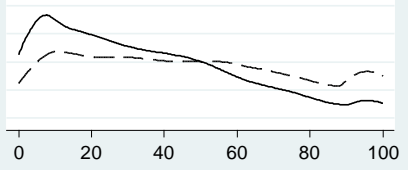

(h) Coleta de Esgoto

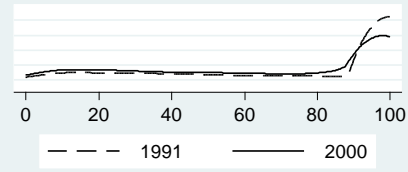

(f) Abastecimento de Água

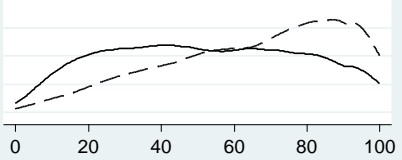

(i) Abastecimento de Água

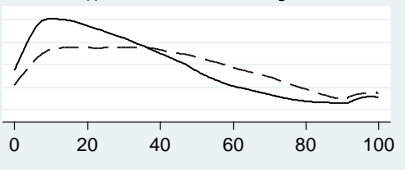

\begin{tabular}{c|c|c|c|c|c|c|c|c|c}
\hline \multirow{2}{*}{$\begin{array}{c}\text { Serviços / } \\
\text { Indicadores } \\
\text { Médios (em \%) }\end{array}$} & \multicolumn{3}{|c|}{ Déficit Total } & \multicolumn{3}{c|}{ Déficit no $1^{\circ}$ Quintil } & \multicolumn{3}{c}{ Déficit no 5 $5^{\circ}$ Quintil } \\
\cline { 2 - 10 } & 1991 & 2000 & $\begin{array}{c}\Delta \% \\
91-00\end{array}$ & 1991 & 2000 & $\begin{array}{c}\Delta \% \\
91-00\end{array}$ & 1991 & 2000 & $\begin{array}{c}\Delta \% \\
91-00\end{array}$ \\
\hline Coleta de Lixo & 63,69 & 46,44 & $-27,08$ & 76,11 & 57,71 & $-24,18$ & 47,48 & 34,53 & $-27,27$ \\
\hline Coleta de Esgoto & 84,72 & 74,89 & $-11,60$ & 89,96 & 79,69 & $-11,42$ & 79,50 & 69,87 & $-12,11$ \\
\hline $\begin{array}{l}\text { Abastecimento } \\
\text { de Água }\end{array}$ & 52,74 & 41,65 & $-21,03$ & 65,51 & 52,54 & $-19,80$ & 40,66 & 31,48 & $-22,58$ \\
\hline
\end{tabular}

$\Delta \%$ 91-00: variação percentual de 1991 a 2000.

Fonte: IBGE, Censos Demográficos de 1991 e 2000. Elaboração própria.

Tais fatos sinalizam a existência de uma relação negativa entre a renda domiciliar per capita e o déficit de acesso aos serviços. Evidências semelhantes foram encontradas por Saiani (2006). Utilizando dados censitários de 2000, o autor chegou a resultados, por meio de estimações econométricas pelo método Probit, que sugerem um aumento da probabilidade de acesso aos serviços de abastecimento de água e de coleta de esgoto à medida que a renda domiciliar per capita aumenta. 
A desigualdade do acesso em função da renda domiciliar pode decorrer da própria capacidade distinta dos domicílios de pagarem pelos serviços. Tal argumento, contudo, não pode ser considerado como a única explicação para o problema, uma vez que os serviços não são cobrados em grande parte dos domicílios - segundo informações da última Pesquisa Nacional de Saneamento Básico (PNSB) realizada em 2000 pelo IBGE, naquele ano, o abastecimento de água não era cobrado em 19\% dos distritos em que o serviço era ofertado; no caso da coleta de esgoto, não havia cobrança em $48 \%$ dos distritos com o serviço; já no caso da limpeza urbana e/ou coleta de lixo, 54\% dos municípios não cobravam pelo serviço. Além disso, são adotados mecanismos de subsídios cruzados em diversas localidades.

Assim, explicações complementares devem ser consideradas. Segundo Bichir (2009), os governantes, ao realizarem investimentos para a expansão e melhoria da infraestrutura urbana em determinadas áreas, valorizam os imóveis lá localizados. Isso pode fazer com que os indivíduos mais pobres não consigam arcar com o consequente aumento dos aluguéis ou, no caso de serem proprietários de seus imóveis, se sintam incentivados a vendê-los, deslocando-se para áreas periféricas desprovidas de serviços de saneamento ambiental.

A desigualdade de acesso em função da renda domiciliar também poderia ser uma decorrência da existência de uma seletividade hierárquica das políticas (SHP) voltadas para o setor. De acordo com essa hipótese da Sociologia, pouco explorada na literatura de Economia, algumas políticas seriam adotadas para beneficiar prioritariamente, e com melhor qualidade, os grupos sociais mais ricos e escolarizados, comtemplando, posteriormente, os demais cidadãos (MARQUES, 2000).

Deve-se ressaltar, ainda, que, mesmo na ausência de cobrança de tarifas, o custo de ligação às redes, no caso do abastecimento de água e da coleta de esgoto, pode inviabilizar o acesso dos mais pobres aos serviços. Além disso, independentemente da capacidade de pagamento e da cobrança ou não pelos serviços, os indivíduos optam pelo acesso se forem capazes de apreciar os benefícios que podem ser gerados pelos mesmos (Mendonça et al., 2004). Essa capacidade decorre de aspectos culturais e educacionais que, por estarem relacionados à renda dos indivíduos, influenciam a desigualdade de acesso.

Rezende et al. (2007) encontraram evidências de uma relação positiva entre acesso domiciliar e nível educacional, considerando os anos de estudo do chefe do domicílio. Os autores argumentam que um maior nível educacional pode tornar os indivíduos mais conscientes em relação a questões ambientais e de saúde, demandando serviços adequados de saneamento ambiental e procurando influenciar as decisões dos governantes nesse sentido. 
Duas consequências diretas do desenvolvimento econômico, apontadas na seção anterior, podem contribuir para esse processo. A primeira é a elevação da concentração populacional em áreas urbanas, que, ao reduzir a distância entre os indivíduos, aumenta a possibilidade destes se organizarem e, consequentemente, exercerem maior pressão política para o atendimento de suas preferências. A segunda é o aumento da parcela da população com níveis mais elevados de educação e, em função disso, com influência política - considerando a hipótese, levantada por Gradstein e Justman (1999), de que existiria uma relação positiva entre participação política e nível educacional. Essas são possíveis justificativas para as tendências, observadas em alguns estudos, de redução do déficit de acesso municipal aos serviços à medida que a população, a taxa de urbanização e a renda per capita se elevam ${ }^{12}$.

As relações entre população e taxa de urbanização podem refletir a existência de economias de escala e de densidade no setor: quanto maior o número de beneficiários e mais eles estiverem concentrados, menor seria o custo de provisão dos serviços. No caso da população, a relação pode decorrer, ainda, do número de potenciais contribuintes, o que viabilizaria a provisão em função do pagamento de tarifas e tributos.

A viabilidade econômica da provisão também é outra possível justificativa para a relação positiva entre a cobertura e a renda per capita, uma vez que municípios mais desenvolvidos tendem a ter uma arrecadação tributária maior e, consequentemente, mais recursos para a realização de investimentos.

Portanto, para avaliar o acesso a serviços de saneamento ambiental, é necessário levar em conta a interação entre os condicionantes da demanda e da oferta desses serviços. Analisando o lado oferta, deve-se considerar o que explicaria a presença das redes de água e de esgoto ou dos sistemas de coleta de lixo nos domicílios. Por se tratar de um setor em que a provisão pública é predominante, aspectos políticos também devem ser considerados. Já pelo lado da demanda, deve-se analisar o que faria os domicílios, existindo a provisão dos serviços, optarem pela não adesão a estes (Rezende et al., 2007).

A breve revisão da literatura realizada até o momento justifica a inclusão de um conjunto de variáveis explicativas nas estimações a serem apresentadas, cujas estratégias e resultados são indicados nas próximas seções. A renda municipal per capita, em valores de 2000, é a principal variável de interesse, por ser a medida de desenvolvimento econômico a partir da qual é avaliada a existência de uma CAK para os déficits de acesso a serviços de saneamento ambiental. Esse indicador é calculado pela razão entre o somatório da renda familiar per capita de todos os domicílios e o número total de domicílios no município, sendo a renda

(12) Ver Motta (2004) e Saiani (2006), por exemplo. 
familiar per capita a razão entre a soma da renda mensal de todos os indivíduos da família residentes no domicílio e o número total de indivíduos.

Uma variável relevante utilizada como controle é a taxa de urbanização municipal - proporção da população total que reside em áreas urbanas. Conforme discutido, esse indicador influencia o déficit de acesso tanto pelo fato de refletir o custo de provisão dos serviços em função da existência de economias de densidade como por representar maior concentração populacional, maior capacidade de organização e, consequentemente, uma influência potencialmente maior sobre os governantes. Esses aspectos também justificam a inclusão, nas estimações, da densidade demográfica dos municípios - razão entre a população total e a área total.

Outras importantes variáveis de controle utilizadas são: (i) porte (tamanho) do município - população total; (ii) anos de estudos - média de anos de estudo das pessoas com 25 anos ou mais de idade residentes no município e (iii) taxa de analfabetismo - percentual de pessoas com 25 anos ou mais de idade residentes no município que não sabem ler nem escrever. De acordo com o que foi discutido, o porte do município reflete a existência de economias de escala e a viabilidade econômica da provisão em função do número de potenciais contribuintes. Já as variáveis educacionais sinalizam maior conscientização ambiental, assim como maior participação e influência política.

Nesse momento, é importante avaliar, preliminarmente, se (e como) os indicadores municipais de déficit de acesso a serviços de saneamento ambiental estão relacionados aos indicadores de desenvolvimento econômico (renda per capita), de concentração populacional (taxa de urbanização e densidade demográfica), de porte (população) e de educação (anos de estudo e taxa de analfabetismo).

Observa-se, na Tabela 1, que, nos três serviços e nos dois anos, os indicadores de déficit de acesso se correlacionavam negativa e significativamente com a renda per capita, a taxa de urbanização, a densidade demográfica, a população e os anos de estudos, mas positiva e significativamente com a taxa de analfabetismo. Essas correlações apontam evidências semelhantes às encontradas na literatura; contudo, o fato de os indicadores de desenvolvimento econômico, de concentração populacional, de porte e de educação também serem correlacionados significativamente entre si não permite avaliar o efeito de cada um sobre o déficit de acesso - ver Tabela A.1 do Apêndice. Além disso, não é possível analisar a existência de uma CAK. Assim, justificam-se as estimações a serem realizadas.

Outra característica dos déficits de acesso aos serviços de saneamento ambiental apontada pela literatura é a existência de uma desigualdade entre as 
regiões geográficas brasileiras ${ }^{13}$. De acordo com a Tabela 2 , as regiões Norte e Nordeste foram as que apresentaram, em relação aos três serviços, nos dois anos, as piores situações de acesso (maiores indicadores municipais médios de déficit), o que se observa tanto no total como nos dois quintis de renda domiciliar. A partir dos argumentos utilizados na presente seção, pode-se dizer que tais situações decorrem, pelo menos parcialmente, do menor desenvolvimento econômico médio (renda per capita média) dos municípios localizados nessas regiões.

\section{Tabela 1}

Brasil: correlações entre os indicadores municipais de déficit de acesso e os indicadores de desenvolvimento econômico, de concentração populacional, de porte e de educação, 1991 e 2000

\begin{tabular}{|c|c|c|c|c|c|c|}
\hline \multirow{2}{*}{$\begin{array}{c}\text { Indicadores } \\
\text { Municipais / Anos }\end{array}$} & \multicolumn{2}{|c|}{ Déficit Total } & \multicolumn{2}{|c|}{$\begin{array}{c}\text { Déficit no } 1^{\circ} \\
\text { Quintil }\end{array}$} & \multicolumn{2}{|c|}{$\begin{array}{c}\text { Déficit no } 5^{\circ} \\
\text { Quintil }\end{array}$} \\
\hline & 1991 & 2000 & 1991 & 2000 & 1991 & 2000 \\
\hline \multicolumn{7}{|c|}{ Coleta de Lixo } \\
\hline Renda per capita & $-0,76^{(a)}$ & $-0,69^{(a)}$ & $-0,72^{(a)}$ & $-0,69^{(a)}$ & $-0,68^{(a)}$ & $-0,60^{(a)}$ \\
\hline Taxa de Urbanização & $-0,80^{(a)}$ & $-0,83^{(a)}$ & $-0,76^{(a)}$ & $-0,81^{(a)}$ & $-0,73^{(a)}$ & $-0,76^{(\mathrm{a})}$ \\
\hline Densidade Demográfica & $-0,23^{(a)}$ & $-0,20^{(a)}$ & $-0,27^{(a)}$ & $-0,22^{(a)}$ & $-0,18^{(a)}$ & $-0,17^{(\mathrm{a})}$ \\
\hline População & $-0,16^{(\mathrm{a})}$ & $-0,14^{(a)}$ & $-0,18^{(\mathrm{a})}$ & $-0,15^{(a)}$ & $-0,13^{(a)}$ & $-0,13^{(a)}$ \\
\hline Anos de Estudo & $-0,72^{(a)}$ & $-0,76^{(a)}$ & $-0,64^{(a)}$ & $-0,74^{(a)}$ & $-0,71^{(\mathrm{a})}$ & $-0,69^{(a)}$ \\
\hline Taxa de Analfabetismo & $0,59^{(\mathrm{a})}$ & $0,60^{(\mathrm{a})}$ & $0,50^{(\mathrm{a})}$ & $0,59^{(\mathrm{a})}$ & $0,59^{(\mathrm{a})}$ & $0,53^{(\mathrm{a})}$ \\
\hline \multicolumn{7}{|c|}{ Coleta de Esgoto } \\
\hline Renda per capita & $-0,57^{(\mathrm{a})}$ & $-0,44^{(a)}$ & $-0,56^{(a)}$ & $-0,44^{(a)}$ & $-0,54^{(a)}$ & $-0,42^{(a)}$ \\
\hline Taxa de Urbanização & $-0,49^{(a)}$ & $-0,51^{(a)}$ & $-0,49^{(a)}$ & $-0,51^{(a)}$ & $-0,47^{(\mathrm{a})}$ & $-0,49^{(a)}$ \\
\hline Densidade Demográfica & $-0,16^{(a)}$ & $-0,16^{(a)}$ & $-0,17^{(a)}$ & $-0,16^{(a)}$ & $-0,15^{(a)}$ & $-0,16^{(a)}$ \\
\hline População & $-0,12^{(a)}$ & $-0,12^{(a)}$ & $-0,13^{(\mathrm{a})}$ & $-0,11^{(\mathrm{a})}$ & $-0,12^{(a)}$ & $-0,12^{(a)}$ \\
\hline Anos de Estudo & $-0,50^{(a)}$ & $-0,45^{(a)}$ & $-0,47^{(a)}$ & $-0,44^{(a)}$ & $-0,50^{(a)}$ & $-0,44^{(a)}$ \\
\hline Taxa de Analfabetismo & $0,44^{(\mathrm{a})}$ & $0,34^{(a)}$ & $0,41^{\text {(a) }}$ & $0,33^{(a)}$ & $0,44^{(\mathrm{a})}$ & $0,33^{\text {(a) }}$ \\
\hline \multicolumn{7}{|c|}{ Abastecimento de Água } \\
\hline Renda per capita & $-0,62^{(a)}$ & $-0,47^{(a)}$ & $-0,62^{(a)}$ & $-0,46^{(a)}$ & $-0,53^{(a)}$ & $-0,35^{(a)}$ \\
\hline Taxa de Urbanização & $-0,80^{(\mathrm{a})}$ & $-0,75^{(a)}$ & $-0,78^{(a)}$ & $-0,73^{(a)}$ & $-0,73^{(a)}$ & $-0,65^{(a)}$ \\
\hline Densidade Demográfica & $-0,21^{(a)}$ & $-0,18^{(a)}$ & $-0,20^{(\mathrm{a})}$ & $-0,17^{(\mathrm{a})}$ & $-0,17^{(\mathrm{a})}$ & $-0,14^{(\mathrm{a})}$ \\
\hline População & $-0,15^{(a)}$ & $-0,12^{(a)}$ & $-0,14^{(a)}$ & $-0,12^{(a)}$ & $-0,13^{(a)}$ & $-0,11^{(\mathrm{a})}$ \\
\hline Anos de Estudo & $-0,66^{(a)}$ & $-0,58^{(a)}$ & $-0,65^{(a)}$ & $-0,57^{(\mathrm{a})}$ & $-0,61^{(a)}$ & $-0,48^{(\mathrm{a})}$ \\
\hline Taxa de Analfabetismo & $0,54^{(a)}$ & $0,42^{(a)}$ & $0,54^{(a)}$ & $0,41^{(a)}$ & $0,48^{(a)}$ & $0,31^{(\mathrm{a})}$ \\
\hline
\end{tabular}

${ }^{(a)}$ Significativo a $1 \% .{ }^{(b)}$ Significativo a $5 \% .{ }^{(c)}$ Significativo a $10 \%$.

Fonte: IBGE, Censos Demográficos de 1991 e 2000. Elaboração própria.

É importante analisar, por último, se existe relação entre os indicadores municipais de déficit de acesso e de desenvolvimento econômico dentro de cada região e como ela se define. A Tabela 3 apresenta a correlação entre essas variáveis. Da mesma forma que para o Brasil como um todo, observa-se que, de

(13) Ver Mejia et al. (2003) e Saiani (2006). 
uma maneira geral, os déficits municipais (total, $1^{\circ}$ quintil e $5^{\circ}$ quintil) nos três serviços se correlacionavam, em 1991 e em 2000, negativa e significativamente com a renda per capita.

Considerando tanto o Brasil como suas regiões, a análise descritiva realizada nesta seção sinaliza que os déficits municipais de acesso tendem a se reduzir à medida que a renda per capita aumenta. Contudo, a análise de correlações não permite inferir com certeza a causalidade e se é o efeito mesmo da renda, uma vez que esta é correlacionada a outras variáveis que também afetariam o acesso. Além disso, não é possível avaliar um comportamento distinto da relação entre os indicadores de déficit de acesso e de renda per capita em diferentes fases do desenvolvimento econômico, o que poderia caracterizar a existência de uma CAK para os serviços de saneamento ambiental. Dessa forma, deve ser ressaltada, mais uma vez, a importância dos testes econométricos que serão realizados.

Tabela 2

Brasil: indicadores municipais médios de déficit de acesso (em \%) e de renda per capita média (valores de 2000), segundo as regiões geográficas, de 1991 e 2000

\begin{tabular}{|c|c|c|c|c|c|c|}
\hline \multicolumn{2}{|c|}{ Indicadores Municipais / Regiões } & Norte & $\begin{array}{c}\text { Nordes- } \\
\text { te }\end{array}$ & $\begin{array}{c}\text { Centro- } \\
\text { Oeste }\end{array}$ & Sul & Sudeste \\
\hline \multicolumn{7}{|c|}{1991} \\
\hline \multirow{3}{*}{ Coleta de Lixo } & Déficit Total & 86,63 & 77,09 & 59,12 & 57,90 & 48,58 \\
\hline & Déficit no $1^{\circ}$ Quintil & 92,54 & 86,13 & 70,90 & 74,21 & 63,57 \\
\hline & Déficit no $5^{\circ}$ Quintil & 75,85 & 62,37 & 41,56 & 37,48 & 32,30 \\
\hline \multirow{3}{*}{$\begin{array}{l}\text { Coleta de } \\
\text { Esgoto }\end{array}$} & Déficit Total & 99,55 & 98,35 & 97,16 & 97,15 & 56,39 \\
\hline & Déficit no $1^{\circ}$ Quintil & 99,88 & 99,13 & 98,50 & 98,74 & 70,63 \\
\hline & Déficit no $5^{\circ}$ Quintil & 98,91 & 97,25 & 95,02 & 94,79 & 43,32 \\
\hline \multirow{3}{*}{$\begin{array}{l}\text { Abastecimento } \\
\text { de Água }\end{array}$} & Déficit Total & 71,80 & 65,40 & 52,02 & 51,57 & 36,33 \\
\hline & Déficit no $1^{\circ}$ Quintil & 79,54 & 76,94 & 62,21 & 66,74 & 50,66 \\
\hline & Déficit no $5^{\circ}$ Quintil & 61,31 & 52,55 & 38,95 & 38,76 & 25,45 \\
\hline \multicolumn{2}{|c|}{ Renda per capita } & 104,46 & 64,93 & 156,49 & 167,60 & 170,80 \\
\hline \multicolumn{7}{|c|}{2000} \\
\hline \multirow{3}{*}{ Coleta de Lixo } & Déficit Total & 69,23 & 61,04 & 37,58 & 40,92 & 30,70 \\
\hline & Déficit no $1^{\circ}$ Quintil & 80,49 & 73,92 & 45,68 & 52,23 & 41,03 \\
\hline & Déficit no $5^{\circ}$ Quintil & 55,43 & 46,32 & 29,63 & 29,67 & 20,81 \\
\hline \multirow{3}{*}{$\begin{array}{l}\text { Coleta de } \\
\text { Esgoto }\end{array}$} & Déficit Total & 98,20 & 84,93 & 93,84 & 89,42 & 42,32 \\
\hline & Déficit no $1^{\circ}$ Quintil & 98,75 & 88,47 & 95,60 & 92,68 & 51,66 \\
\hline & Déficit no $5^{\circ}$ Quintil & 96,77 & 81,07 & 90,95 & 85,25 & 33,91 \\
\hline \multirow{3}{*}{$\begin{array}{l}\text { Abastecimento } \\
\text { de Água }\end{array}$} & Déficit Total & 61,15 & 50,02 & 38,12 & 42,18 & 27,86 \\
\hline & Déficit no $1^{\circ}$ Quintil & 72,24 & 64,16 & 43,51 & 52,18 & 37,27 \\
\hline & Déficit no $5^{\circ}$ Quintil & 50,84 & 36,06 & 32,71 & 32,99 & 19,86 \\
\hline \multicolumn{2}{|c|}{ Renda per capita } & 120,47 & 85,16 & 209,16 & 233,69 & 222,96 \\
\hline
\end{tabular}

Fonte: IBGE, Censos Demográficos de 1991 e 2000. Elaboração própria. 
Déficit de acesso a serviços de saneamento ambiental: evidências de uma Curva Ambiental de Kuznets...

Tabela 3

Brasil: correlações entre os indicadores municipais de déficit de acesso e de renda per capita, segundo as regiões geográficas, de 1991 e 2000

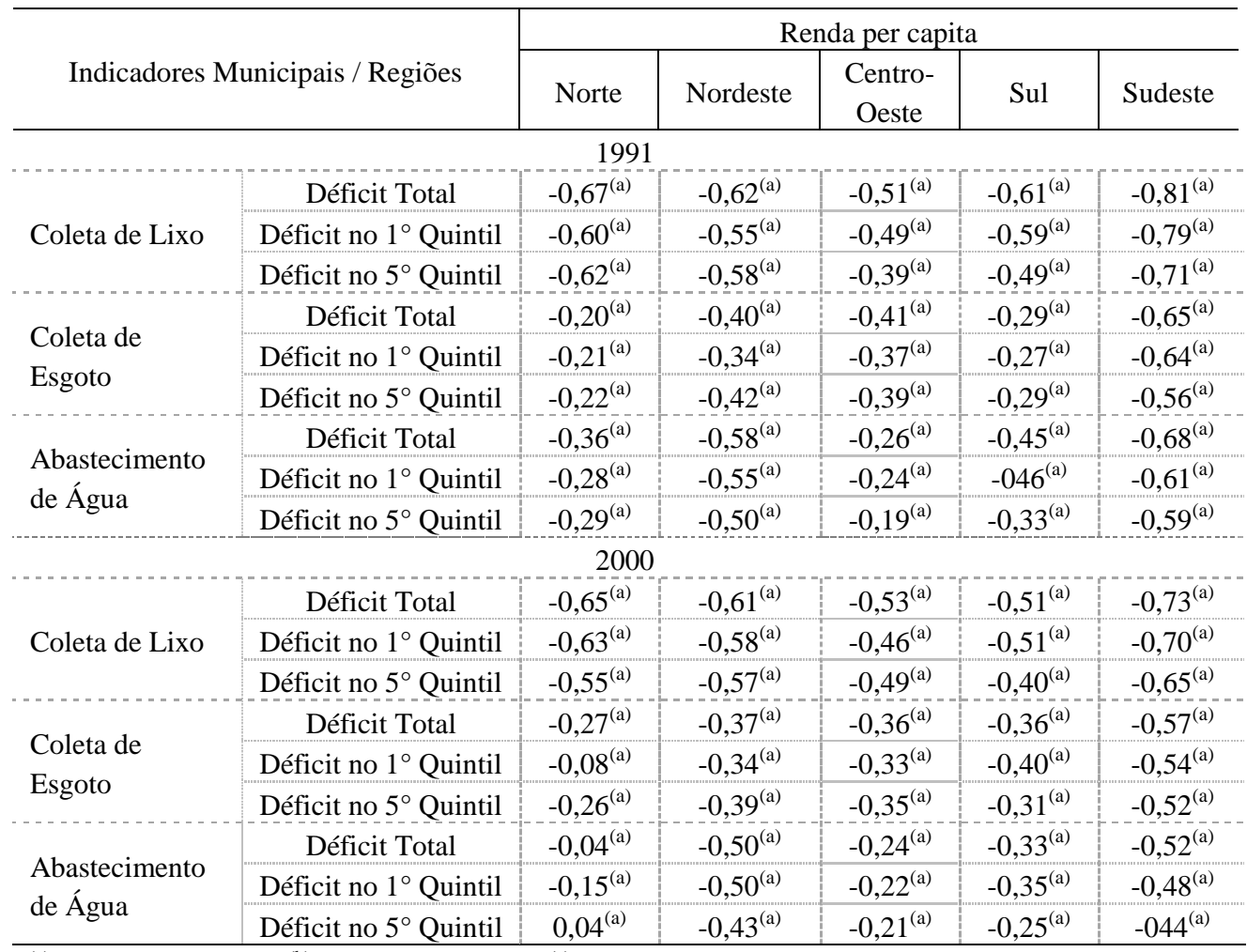

\footnotetext{
${ }^{\text {(a) }}$ Significativo a $1 \% .{ }^{\text {(b) }}$ Significativo a $5 \%$. ${ }^{\text {(c) }}$ Significativo a $10 \%$.

Fonte: IBGE, Censos Demográficos de 1991 e 2000. Elaboração própria.
}

\section{Estratégias de estimação}

A hipótese da Curva Ambiental de Kuznets (CAK) pode ser testada, com dados em cross-section, por meio de estimações de modelos baseados na equação (1), que considera um polinômio de segundo grau em relação à medida de desenvolvimento econômico - o que foi feito em diversos estudos.

$Y_{i}=\beta_{0}+\beta_{1} D_{i}+\beta_{2} D_{i}^{2}+\varepsilon_{i}$

sendo $Y_{i}$ uma medida de degradação ambiental da localidade $i ; D_{i}$ uma medida de desenvolvimento econômico da localidade $i$ - a renda per capita é a mais utilizada - e $\varepsilon_{i}$ o erro aleatório.

Para que a hipótese seja corroborada, ou seja, para que a relação entre a degradação ambiental e o desenvolvimento econômico apresente o formato de um "U invertido", os coeficientes $\beta_{1}$ e $\beta_{2}$, além de significativos, devem respeitar as seguintes condições de sinais: $\beta_{1}>0$ e $\beta_{2}<0$. 
O uso de dados em cross-section para testar a existência da CAK pode ser contestado em função de a relação decorrer de processos dinâmicos de transformações na economia - conforme apontado na primeira seção -, o que justifica a utilização de dados em painel. Além disso, o emprego de métodos em painel pode diminuir possíveis problemas de viés decorrentes das características específicas de cada localidade, que induziriam trajetórias únicas e que não são controladas nas estimações seccionais.

Entre as abordagens com dados em painel, a de efeitos fixos (estimador Within) é apontada pela literatura como a mais adequada para testar a validade da CAK, uma vez que permite estimar se indicadores de degradação ambiental de diferentes localidades seguem as mesmas trajetórias ao longo do desenvolvimento econômico, mesmo com interceptos distintos. A vantagem da abordagem decorre da possibilidade de se corrigir o potencial viés associado à correlação entre variáveis omitidas, fixas no tempo, e os regressores incluídos no modelo, assim como o efeito comum às unidades seccionais, mas que variam ao longo do tempo (Fields; Jakubson, 1994).

O teste da hipótese da CAK pelo método de efeitos fixos é feito por meio da estimação de modelos baseados na equação (2) - a hipótese continua a ser corroborada com $\beta_{1}>0$ e $\beta_{2}<0$ quando os dois coeficientes são significativos.

$Y_{i t}=\beta_{0}+\beta_{1} D_{i t}+\beta_{2} D_{i t}^{2}+u_{i}+T_{\mathrm{t}}+\varepsilon_{i t}$

sendo $Y_{i t}$ uma medida de degradação ambiental da localidade $i$ no período $t ; D_{i t}$ uma medida de desenvolvimento econômico da localidade $i$ no período $t ; u_{i}$ um conjunto de características não observáveis da localidade $i$ constantes no tempo (efeitos fixos); $T_{\mathrm{t}}$ um conjunto de características constantes entre as localidades, mas que variam no tempo - geralmente, são utilizadas dummies de períodos - e $\varepsilon_{i t}$ o erro aleatório.

As equações (1) e (2) mostram formas de testar se a relação entre a degradação ambiental e o desenvolvimento econômico assume o formato de um "U invertido". Contudo, conforme apontado anteriormente, alguns estudos encontraram evidências de formatos diferentes para a relação. Nesse sentido, pode ser destacado o trabalho de Jones e Manuelli (1998) no qual foi constatado que, para alguns indicadores, essa relação assumiria o formato de um "N". Para testar, pelo método de efeitos fixos, a hipótese da CAK nesse formato, inclui-se, em (2), um polinômio de terceiro grau em relação à medida de desenvolvimento econômico, estimando modelos baseados na equação (3).

$Y_{i t}=\beta_{0}+\beta_{1} D_{i t}+\beta_{2} D_{i t}^{2}+\beta_{3} D_{i t}^{3}+u_{i}+T_{\mathrm{t}}+\varepsilon_{i t}$

A hipótese da relação no formato de um "N" é corroborada quando: (i) os coeficientes $\beta_{1}, \beta_{2}$ e $\beta_{3}$ são significativos; (ii) $\beta_{1}>0$; (iii) $\beta_{2}<0$ e (iv) $\beta_{3}>0$. 
Se $\beta_{1}>0$ e $\beta_{2}<0$, mas $\beta_{3}$ é não significativo ou menor que zero, a relação assume o formato tradicional de um "U invertido".

A validação da CAK apenas por meio da estimação de modelos baseados nas equações (1), (2) e (3) também pode ser questionada, uma vez que alguns estudos encontraram evidências favoráveis ao considerar, conjuntamente, países desenvolvidos e em desenvolvimento. Contudo, ao considerarem amostras desagregadas, as evidências não foram tão favoráveis. Esse fato pode sinalizar que os resultados encontrados para a amostra total poderiam refletir outras diferenças entre os países e não apenas a relação entre degradação ambiental e desenvolvimento econômico.

Para lidar com esse problema potencial, podem ser incluídas, nas estimações, variáveis de controle que refletem características distintas das localidades e que influenciariam a degradação ambiental. Essa sugestão foi adotada em alguns estudos que estimaram modelos baseados na equação (3), mas incorporando um conjunto de características observáveis (controles) da localidade $i$ no período $t\left(W_{i t}\right)$ - conforme a equação (4).

$Y_{i t}=\beta_{0}+\beta_{1} D_{i t}+\beta_{2} D_{i t}^{2}+\beta_{3} D_{i t}^{3}+\beta_{4} W_{i t}+u_{i}+T_{\mathrm{t}}+\varepsilon_{i t}$

A hipótese da relação no formato de um "N" continua a ser corroborada quando: (i) $\beta_{1}, \beta_{2}$ e $\beta_{3}$ são significativos; (ii) $\beta_{1}>0$; (iii) $\beta_{2}<0$ e (iv) $\beta_{3}>0$. Por outro lado, a relação assume o formato de um "U invertido" se $\beta_{1}>0, \beta_{2}<0$ e $\beta_{3}<0$ (ou não significativo).

No presente artigo, serão estimados modelos baseados nas equações (3) e (4) - especificações I e II, respectivamente -, utilizando, como medidas de degradação ambiental $\left(Y_{i t}\right)$, os três indicadores de déficit de acesso apresentados na seção anterior (total, $1^{\circ}$ quintil e $5^{\circ}$ quintil) para os três serviços considerados (coleta de lixo, coleta de esgoto e abastecimento de água). Conforme já apontado, esses indicadores foram calculados, a partir de dados censitários, para todos os municípios brasileiros com informações disponibilizadas em 1991 e em 2000. Assim, $i$ representa os municípios brasileiros e $t$ os anos censitários. Como medida de desenvolvimento econômico, será utilizada a renda per capita municipal, variável que também foi apresentada na seção anterior.

É importante ressaltar, mais uma vez, que a análise de três serviços também permite testar a robustez dos resultados de modo que seja possível averiguar a existência ou não de uma tendência comum das políticas públicas voltadas aos serviços de saneamento ambiental. Além disso, deve-se destacar que 
será utilizado o método de efeitos fixos, por ser apontado pela literatura como o mais adequado para testar a validade da $\mathrm{CAK}^{14}$.

As variáveis de controle utilizadas nas estimações $\left(W_{i t}\right)$, apresentadas no Quadro 1, representam um conjunto de características observáveis dos municípios que poderiam influenciar os déficits de acesso aos serviços e, consequentemente, a degradação ambiental. A Tabela A.2 do Apêndice mostra as estatísticas descritivas dessas variáveis em cada ano. A adoção de parte desses controles é justificada pelas revisões da literatura realizadas nas duas primeiras seções, que mostram possíveis determinantes, além do próprio déficit de acesso, da relação do tipo da CAK - a exemplo das variáveis taxa de urbanização, densidade demográfica, população, anos de estudo, taxa de analfabetismo, razão de desigualdade e não branco $^{15}$.

Quadro 1

Descrição das variáveis de controles: indicadores municipais

\begin{tabular}{|c|c|}
\hline Indicadores Municipais & Descrição \\
\hline Taxa de Urbanização & Razão entre a população residente em áreas urbanas e a população total \\
\hline Densidade Demográfica & Razão entre a população total e a área total (população/km²) \\
\hline População & População total \\
\hline Anos de Estudo & Média dos anos de estudo das pessoas de 25 anos ou mais de idade \\
\hline Taxa de Analfabetismo & $\begin{array}{l}\text { Percentual de pessoas de } 25 \text { anos ou mais de idade que não sabem ler } \\
\text { nem escrever }\end{array}$ \\
\hline Razão de Desigualdade & $\begin{array}{l}\text { Razão entre a renda média do décimo mais rico da população e a renda } \\
\text { média dos quatro décimos mais pobres }\end{array}$ \\
\hline Não Branco & Razão entre a população não branca e a população total \\
\hline Energia e Televisão & $\begin{array}{l}\text { Percentual de pessoas que vivem em domicílios com energia elétrica e } \\
\text { aparelho de televisão em cores ou preto e branco }\end{array}$ \\
\hline Carro & $\begin{array}{l}\text { Percentual de pessoas que vivem em domicílios com automóvel de } \\
\text { passeio ou veículo utilitário }\end{array}$ \\
\hline Telefone & $\begin{array}{l}\text { Percentual de pessoas que vivem em domicílios com linha convencional } \\
\text { de telefone instalada, própria, alugada ou ramal }\end{array}$ \\
\hline Geladeira & Percentual de pessoas que vivem em domicílios com geladeira ou freezer \\
\hline Abaixo de 18 Anos & Razão entre a população abaixo de 18 anos e a população total \\
\hline Acima de 65 Anos & Razão entre a população acima de 65 anos e a população total \\
\hline Área & Área total $\left(\mathrm{km}^{2}\right)$ \\
\hline
\end{tabular}

(14) Os resultados do teste de Hausman serão reportados para validar a melhor adequação dessa abordagem em comparação à de efeitos aleatórios.

(15) As variáveis razão de desigualdade e não branco indicam, respectivamente, a desigualdade de renda e a heterogeneidade étnica do município. Conforme apontado na primeira seção, essas variáveis podem influenciar a distribuição mais equitativa por parte do poder político e, consequentemente, as possibilidades daqueles que sofrem relativamente mais com o custo da degradação de reivindicarem a adoção de medidas preservacionistas (Torras; Boyce, 1998). No caso do saneamento ambiental, poderiam pressionar os governantes a ofertarem os serviços. 
Na ausência de teoria ou estudos prévios, foram escolhidas variáveis que, a partir da literatura de outros serviços públicos, supostamente podem influenciar o acesso a saneamento ambiental. As variáveis energia e televisão, telefone, carro e geladeira são utilizadas como proxies de riqueza (ou renda permanente). As variáveis abaixo de 18 anos e acima de 65 anos foram incluídas com o intuito de capturar características distintas da demanda, uma vez que indivíduos nessas faixas etárias necessitam de cuidados especiais, o que poderia resultar em maiores pressões sociais por melhorias e ampliação dos serviços.

Além disso, uma maior participação da população acima de 65 anos pode sinalizar um município mais antigo, mais consolidado, com menor dinâmica demográfica e demanda por expansão de habitações e infraestrutura urbana. Assim, deve-se esperar um menor déficit de acesso aos serviços. Já no caso de municípios com maior participação de jovens, a dinâmica de crescimento populacional tende a ser maior, influenciando a demanda por habitações e infraestrutura urbana. Dessa forma, por se tratar de municípios em expansão, os indicadores de acesso, em um dado momento, devem ser inferiores.

A área de um município costuma não variar muito ao longo do tempo. Contudo, o Brasil apresentou um aumento significativo no número de municípios durante a década de 1990 por meio do desmembramento de outros já existentes. De uma maneira geral, os novos municípios originaram-se de distritos pequenos e marginais, com indicadores de infraestrutura, econômicos e sociais inferiores aos dos municípios que os deram origem. Assim, corre-se o risco de haver uma distorção no sentido de que o simples desmembramento teria provocado uma melhoria nos indicadores médios dos municípios originais, justificando a inclusão da variável área nas estimações ${ }^{16}$. Outras variáveis, como população, densidade demográfica e taxa de urbanização, também podem captar o mesmo efeito. Além disso, deve-se ressaltar que, por se tratar de um painel balanceado para apenas dois anos (1991 e 2000), os municípios criados durante esse período são desconsiderados nas estimações ${ }^{17}$.

As variáveis de controle $\left(W_{i t}\right)$ e a renda municipal per capita $\left(D_{i t}\right)$ são utilizadas na forma logarítmica, evitando-se casos em que os coeficientes têm muitas casas decimais em função da grande variação das mesmas. Dessa forma, a interpretação dos coeficientes deve ser feita da seguinte maneira: "uma variação de $1 \%$ em X está associada a uma variação de Y pontos percentuais (p.p.) na variável

(16) Tal indicador pode refletir, ainda, características específicas dos municípios que deram origem aos novos e diferenças de custos em função do tamanho do território.

(17) Uma alternativa seria utilizar Áreas Mínimas Comparáveis (AMCs) ao invés de municípios, mas, como estes são os titulares dos serviços, acredita-se que seja mais adequado utilizá-los como unidades de análises. Áreas Mínimas Comparáveis (AMCs) são delimitações geográficas estáveis ao longo do tempo, dessa forma, mesmo que um município se desmembre em vários, todos continuarão pertencendo á mesma $\mathrm{AMC}$, tornando possíveis as comparações dos dados municipais ao longo do tempo por meio de agregação dos dados específicos. 
dependente". Não foram considerados os logaritmos dos déficits municipais de acesso $\left(Y_{i t}\right)$ - variáveis dependentes - em função do fato de esses indicadores serem iguais a zero em alguns municípios, o que faria com que algumas observações fossem perdidas.

Além das variáveis observáveis, são consideradas: (i) características não observáveis $\left(u_{i}\right)$ diferentes entre os municípios, mas constantes ao longo do tempo (efeitos fixos) - conforme apontado anteriormente, aspectos institucionais e culturais específicos de cada município, que não variam ao longo do tempo, também podem influenciar o déficit de acesso aos serviços e a degradação ambiental - e (ii) uma dummy de ano $\left(T_{\mathrm{t}}\right)$, igual a zero em 1991 e a um em 2000, que captaria o efeito de características não observáveis constantes entre os municípios, mas que variam ao longo do tempo, assim como uma tendência comum de variação dos indicadores no período.

É importante destacar que um sério problema de corroborar a hipótese da CAK por meio de estimações que consideram localidades de países distintos é a relativa incomparabilidade dos dados, uma vez que estes se remetem à diferentes fontes de informações. Dessa forma, os resultados obtidos em estudos internacionais podem sofrer a influência de erros de medida (viés) que decorrem de diferenças nos questionários utilizados para a coleta das informações e de fatores que podem intervir na aferição dos indicadores. Assim, uma vantagem do presente estudo é considerar os municípios brasileiros como unidades de análise, o que reduz o viés de erro de medida, uma vez que os dados são obtidos, de uma maneira geral, na mesma fonte de informações (IBGE).

No presente estudo, são realizadas, ainda, estimações a partir da equação (4), excluindo, da amostra total, os municípios que, em 2000, possuíam prestadores privados - especificação III; ou seja, os modelos são estimados apenas para os municípios que possuíam prestadores públicos nos dois anos analisados (1991 e 2000). Isso é feito para a coleta de esgoto e o abastecimento de água - no caso da coleta de lixo, não há informações que permitam essa desagregação ${ }^{18}$. Dessa forma, é possível testar a robustez dos resultados, desconsiderando potenciais efeitos da desestatização ${ }^{19}$.

(18) A participação privada nos serviços de coleta de esgoto e de abastecimento de água teve início a partir de 1995 com a inclusão dos serviços públicos no Plano Nacional de Desestatização (PND) e a promulgação da Lei de Concessões (Lei n. 8.987). Devido a uma série de entraves, essa participação era ainda pequena em 2000, restringindo-se a aproximadamente $2 \%$ dos municípios - ver Toneto Júnior e Saiani (2006). As informações sobre o tipo de prestador em cada município são disponibilizadas pelo Ministério das Cidades e pela Associação Brasileira das Concessionárias Privadas dos Serviços Públicos de Água e Esgoto (ABCON).

(19) Segundo Galiani et al. (2005), a privatização pode reduzir o acesso dos mais pobres em função de aumentos de tarifas, maior intolerância à inadimplência, redução de subsídios e investimentos apenas em áreas com maior lucratividade. 
Outro teste de robustez consiste em estimações semelhantes às da especificação II, mas que consideram indicadores de déficit de acesso construídos apenas com informações dos domicílios urbanos. Esse teste é adotado uma vez que a concentração populacional nas áreas urbanas pode resultar em economias de escala e de densidade assim como em uma maior pressão da população por serviços mais adequados, destacando-se ainda os diferenciais de rendimento entre trabalhadores urbanos e rurais. Esses fatores levariam, potencialmente, a um maior acesso em municípios mais urbanizados independentemente de seu desenvolvimento econômico. Deve-se ressaltar, mais uma vez, que a opção pela utilização de indicadores de acesso urbano apenas como teste de robustez se deve ao fato de que situações inadequadas dos serviços geram externalidades ambientais a despeito da localização dos domicílios.

Adicionalmente, são realizadas estimações, baseando-se na equação (4), com a amostra desagregada em regiões geográficas (Norte, Nordeste, Centro-Oeste, Sul e Sudeste) - especificação $I V$-, de modo que seja possível comparar se também são observadas relações do tipo da CAK. Assim, tal desagregação permitirá avaliar se os resultados encontrados para a amostra total refletem diferenças regionais entre os municípios e não apenas a relação entre degradação ambiental e desenvolvimento econômico.

Deve-se apontar, por último, que a análise de indicadores de déficit por quintis de renda domiciliar, além de ser um teste de robustez para o déficit total na verificação da existência da CAK, permite avaliar se as políticas públicas voltadas para o setor levam em conta o perfil de renda dos consumidores, o que refletiria uma maior preocupação com retornos econômicos, e não apenas com os retornos sociais que os serviços podem gerar - na introdução, foram apontadas as externalidades geradas sobre o meio ambiente e a saúde pública. Seguindo as revisões da literatura realizadas nas primeiras seções, diferenças entre os quintis poderiam também refletir conscientizações ambientais e capacidades distintas de exercer pressão.

\section{Análise dos resultados}

A análise realizada na presente seção foca os resultados que permitem validar ou não a hipótese da existência da CAK para o caso do déficit de acesso a serviços de saneamento ambiental nos municípios brasileiros. Devido à restrição de espaço e à menor importância para a discussão proposta, os resultados para a maioria das variáveis de controle não serão reportados - a avaliação dos controles será realizada apenas para o caso da amostra total. De uma maneira geral, estes estão de acordo com o previsto pelas análises das primeiras seções. 
Conforme também esperado, o teste de Hausman apontou, em todas as estimações, a melhor adequação do método de efeitos fixos - a literatura defende a superioridade desse método para o teste da existência da CAK. Isso sinaliza que aspectos institucionais e culturais específicos de cada município, que não variam ao longo do tempo, também influenciam o déficit de acesso a serviços e a consequente a degradação ambiental.

A Tabela 4 apresenta os resultados das estimações das especificações de I a III para a variável dependente déficit total. Os resultados da especificação I sinalizam, para os casos da coleta de lixo e de esgoto, a existência de uma relação entre os déficits municipais de acesso e a renda per capita, não no tradicional formato de "U invertido" da CAK, mas sim no formato de um "N", uma vez que os coeficientes do polinômio de terceiro grau em relação à renda municipal per capita são significativos e respeitam a regra de sinais apresentada anteriormente: (i) positivo para a variável em nível; (ii) negativo para essa variável ao quadrado e (iii) positivo para a variável ao cubo. Ou seja, os déficits de acesso a lixo e esgoto aumentam em níveis iniciais de desenvolvimento e diminuem a partir de certo nível, mas essa queda não se sustenta no longo prazo uma vez que os déficits voltam a aumentar. No caso do abastecimento de água, os coeficientes também apresentam os sinais esperados, mas são não significativos para a variável renda per capita em nível e ao quadrado.

$\mathrm{Na}$ especificação II, foram consideradas variáveis de controle para lidar com o problema potencial dos resultados encontrados para a amostra total refletirem outras diferenças entre os municípios, e não apenas a relação entre a degradação ambiental e o desenvolvimento econômico. Na coleta de lixo, a CAK no formato de um " $N$ " continua a ser observada. Já na coleta de esgoto, o coeficiente da variável renda per capita apresenta o sinal esperado, mas passa a ser não significativo. No abastecimento de água, por sua vez, os coeficientes do polinômio de terceiro grau da medida de desenvolvimento econômico apresentam os sinais esperados e passam a ser significativos.

A especificação III exclui da amostra os municípios que privatizaram a coleta de esgoto ou o abastecimento de água entre 1991 e 2000, desconsiderando potenciais efeitos desse processo sobre o acesso. Para essa amostra reduzida, observa-se a existência de uma CAK no formato de um "N" nos dois serviços analisados - coeficientes do polinômio de terceiro grau em relação à renda per capita com os sinais esperados e significativos. 
Déficit de acesso a serviços de saneamento ambiental: evidências de uma Curva Ambiental de Kuznets...

Tabela 4

Resultados das estimações das especificações de I a III: variável dependente déficit total

\begin{tabular}{|c|c|c|c|c|c|c|c|c|}
\hline \multirow{3}{*}{$\begin{array}{c}\text { Variáveis / } \\
\text { Especificações }\end{array}$} & \multicolumn{8}{|c|}{ Déficit Total } \\
\hline & \multicolumn{2}{|c|}{ Lixo } & \multicolumn{3}{|c|}{ Esgoto } & \multicolumn{3}{|c|}{ Água } \\
\hline & $\mathrm{I}$ & II & $\mathrm{I}$ & II & III & I & II & III \\
\hline $\begin{array}{l}\text { Renda Municipal } \\
\text { per capita }\end{array}$ & $\begin{array}{l}5,573^{(a)} \\
(0,371)\end{array}$ & $\begin{array}{l}5,466^{(\mathrm{a})} \\
(0,393)\end{array}$ & $\begin{array}{l}1,761^{(\mathrm{a})} \\
(0,471)\end{array}$ & $\begin{array}{c}0,786 \\
(0,511)\end{array}$ & $\begin{array}{l}1,017^{(\mathrm{c})} \\
(0,523)\end{array}$ & $\begin{array}{c}0,023 \\
(0,367)\end{array}$ & $\begin{array}{l}1,023^{(\mathrm{a})} \\
(0,376)\end{array}$ & $\begin{array}{l}0,818^{(\mathrm{b})} \\
(0,381)\end{array}$ \\
\hline $\begin{array}{l}\text { Renda Municipal } \\
\text { per capita }^{2}\end{array}$ & $\begin{array}{c}-1,190^{(a)} \\
(0,078)\end{array}$ & $\begin{array}{l}-1,159^{(a)} \\
(0,081)\end{array}$ & $\begin{array}{l}-0,384^{(a)} \\
(0,098)\end{array}$ & $\begin{array}{l}-0,198^{(\mathrm{c})} \\
(0,105)\end{array}$ & $\begin{array}{c}-0,247^{(\mathrm{b})} \\
(0,108)\end{array}$ & $\begin{array}{l}-0,096 \\
(0,076)\end{array}$ & $\begin{array}{l}-0,236^{(a)} \\
(0,077)\end{array}$ & $\begin{array}{l}-0,194^{(\mathrm{b})} \\
(0,078)\end{array}$ \\
\hline $\begin{array}{l}\text { Renda Municipal } \\
\text { per capita }^{3}\end{array}$ & $\begin{array}{l}0,082^{(\mathrm{a})} \\
(0,005)\end{array}$ & $\begin{array}{l}0,079^{(\mathrm{a})} \\
(0,006)\end{array}$ & $\begin{array}{l}0,027^{(\mathrm{a})} \\
(0,007)\end{array}$ & $\begin{array}{l}0,016^{(\mathrm{b})} \\
(0,007)\end{array}$ & $\begin{array}{l}0,019^{(\mathrm{a})} \\
(0,007)\end{array}$ & $\begin{array}{l}0,012^{(\mathrm{b})} \\
(0,005)\end{array}$ & $\begin{array}{l}0,017^{(\mathrm{a})} \\
(0,005)\end{array}$ & $\begin{array}{l}0,014^{(\mathrm{a})} \\
(0,005)\end{array}$ \\
\hline $\begin{array}{l}\text { Taxa de } \\
\text { Urbanização }\end{array}$ & & $\begin{array}{l}-0,083^{(a)} \\
(0,015)\end{array}$ & & $\begin{array}{l}0,028^{(\mathrm{b})} \\
(0,013)\end{array}$ & $\begin{array}{l}0,030^{(\mathrm{b})} \\
(0,013)\end{array}$ & & $\begin{array}{l}-0,121^{(a)} \\
(0,015)\end{array}$ & $\begin{array}{l}-0,126^{(a)} \\
(0,015)\end{array}$ \\
\hline $\begin{array}{l}\text { Densidade } \\
\text { Demográfica }\end{array}$ & & $\begin{array}{l}-0,014^{(a)} \\
(0,005)\end{array}$ & & $\begin{array}{l}0,020^{(\mathrm{a})} \\
(0,002)\end{array}$ & $\begin{array}{l}0,020^{(\mathrm{a})} \\
(0,002)\end{array}$ & & $\begin{array}{l}-0,009^{(a)} \\
(0,002)\end{array}$ & $\begin{array}{l}-0,009^{(\mathrm{a})} \\
(0,002)\end{array}$ \\
\hline População & & $\begin{array}{l}-0,067^{(a)} \\
(0,022)\end{array}$ & & $\begin{array}{l}-0,062^{(b)} \\
(0,028)\end{array}$ & $\begin{array}{c}-0,060^{(\mathrm{b})} \\
(0,029)\end{array}$ & & $\begin{array}{l}-0,118^{(a)} \\
(0,024)\end{array}$ & $\begin{array}{l}-0,130^{(a)} \\
(0,025)\end{array}$ \\
\hline Anos de Estudo & & $\begin{array}{l}-0,036^{(\mathrm{c})} \\
(0,021)\end{array}$ & & $\begin{array}{c}0,021 \\
(0,021)\end{array}$ & $\begin{array}{c}0,021 \\
(0,022)\end{array}$ & & $\begin{array}{l}-0,013 \\
(0,018)\end{array}$ & $\begin{array}{l}-0,025 \\
(0,018)\end{array}$ \\
\hline $\begin{array}{l}\text { Taxa de } \\
\text { Analfabetismo }\end{array}$ & & $\begin{array}{c}-0,042^{(b)} \\
(0,019)\end{array}$ & & $\begin{array}{l}0,043^{(\mathrm{a})} \\
(0,016)\end{array}$ & $\begin{array}{l}0,047^{(\mathrm{a})} \\
(0,017)\end{array}$ & & $\begin{array}{c}0,010 \\
(0,018)\end{array}$ & $\begin{array}{c}0,019 \\
(0,017)\end{array}$ \\
\hline $\begin{array}{l}\text { Razão de } \\
\text { Desigualdade }\end{array}$ & & $\begin{array}{l}0,019^{(\mathrm{a})} \\
(0,004)\end{array}$ & & $\begin{array}{l}0,011^{(\mathrm{b})} \\
(0,005)\end{array}$ & $\begin{array}{l}0,011^{(\mathrm{b})} \\
(0,005)\end{array}$ & & $\begin{array}{l}0,011^{(\mathrm{b})} \\
(0,005)\end{array}$ & $\begin{array}{l}0,010^{(b)} \\
(0,005)\end{array}$ \\
\hline Não Branco & & $\begin{array}{l}-0,002 \\
(0,007)\end{array}$ & & $\begin{array}{l}-0,001 \\
(0,007)\end{array}$ & $\begin{array}{l}-0,002 \\
(0,007)\end{array}$ & & $\begin{array}{l}-0,002 \\
(0,006)\end{array}$ & $\begin{array}{l}-0,001 \\
(0,006)\end{array}$ \\
\hline $\begin{array}{l}\text { Abaixo de } 18 \\
\text { Anos }\end{array}$ & & $\begin{array}{c}0,017 \\
(0,051)\end{array}$ & & $\begin{array}{l}0,348^{(\mathrm{a})} \\
(0,062)\end{array}$ & $\begin{array}{l}0,367^{(\mathrm{a})} \\
(0,064)\end{array}$ & & $\begin{array}{c}0,049 \\
(0,050)\end{array}$ & $\begin{array}{c}0,039 \\
(0,050)\end{array}$ \\
\hline $\begin{array}{l}\text { Acima de } 65 \\
\text { Anos }\end{array}$ & & $\begin{array}{l}0,034^{(\mathrm{b})} \\
(0,013)\end{array}$ & & $\begin{array}{l}0,080^{(a)} \\
(0,014)\end{array}$ & $\begin{array}{l}0,081^{(\mathrm{a})} \\
(0,015)\end{array}$ & & $\begin{array}{l}-0,005 \\
(0,013)\end{array}$ & $\begin{array}{c}0,002 \\
(0,013)\end{array}$ \\
\hline Área & & $\begin{array}{l}0,024^{(\mathrm{c})} \\
(0,014)\end{array}$ & & $\begin{array}{l}0,098^{(\mathrm{a})} \\
(0,020)\end{array}$ & $\begin{array}{l}0,093^{(\mathrm{a})} \\
(0,020)\end{array}$ & & $\begin{array}{c}-0,086^{(a)} \\
(0,016)\end{array}$ & $\begin{array}{c}-0,077^{(a)} \\
(0,016)\end{array}$ \\
\hline Dummy Ano & $\begin{array}{c}-0,178^{(a)} \\
(0,004)\end{array}$ & $\begin{array}{l}-0,159^{(a)} \\
(0,014)\end{array}$ & $\begin{array}{c}-0,119^{(a)} \\
(0,005)\end{array}$ & $\begin{array}{l}-0,121^{\text {(a) }} \\
(0,016)\end{array}$ & $\begin{array}{c}-0,120^{(a)} \\
(0,016)\end{array}$ & $\begin{array}{c}-0,135^{(a)} \\
(0,004)\end{array}$ & $\begin{array}{l}-0,046^{(a)} \\
(0,014)\end{array}$ & $\begin{array}{l}-0,054^{(a)} \\
(0,014)\end{array}$ \\
\hline $\begin{array}{l}\text { Proxies de } \\
\text { Riqueza }\end{array}$ & Não & Sim & Não & Sim & Sim & Não & Sim & Sim \\
\hline Observações & 9.680 & 9.642 & 9.981 & 9.943 & 9.834 & 9.981 & 9.943 & 9.821 \\
\hline Grupos & 5.500 & 5.483 & 5.500 & 5.483 & 5.451 & 5.500 & 5.483 & 5.447 \\
\hline Prob $>F$ & 0,000 & 0,000 & 0,000 & 0,000 & 0,000 & 0,000 & 0,000 & 0,000 \\
\hline $\begin{array}{l}\text { Teste de } \\
\text { Hausman }\end{array}$ & $774,6^{(\mathrm{a})}$ & $499,1^{(\mathrm{a})}$ & $325,4^{(\mathrm{a})}$ & $748,9^{(\mathrm{a})}$ & $680,6^{(\mathrm{a})}$ & $385,9^{(a)}$ & $764,1^{(\mathrm{a})}$ & $728,4^{(\mathrm{a})}$ \\
\hline
\end{tabular}

Obs.: erros-padrão entre parênteses. ${ }^{(a)}$ Significativo a $1 \% .{ }^{\text {(b) }}$ Significativo a $5 \% .{ }^{\text {(c) }}$ Significativo a $10 \%$.

A inclusão de controles nas especificações II e III também permite avaliar quais variáveis podem ser apontadas como determinantes dos déficits de acesso aos serviços de saneamento ambiental. Os resultados encontrados para algumas dessas variáveis são comentados a seguir. É importante apontar que diferenças dos 
coeficientes dos controles entre os serviços podem decorrer de preferências, políticas públicas e custos específicos. Uma análise mais pormenorizada desses fatores foge do escopo do presente estudo, mas pode servir de motivação para trabalhos futuros.

Os coeficientes da taxa de urbanização e da densidade demográfica são negativos e significativos no caso da coleta de lixo e do abastecimento de água. De acordo com as revisões da literatura realizadas nas primeiras seções, esses resultados podem refletir um menor custo de provisão em locais com maior concentração populacional em função da existência de economias de densidade no setor, assim como da capacidade mais efetiva dos cidadãos de se organizarem e exercerem pressão sobre os governantes para o atendimento de suas preferências. No caso do esgoto, os coeficientes desses controles são positivos e significativos, o que pode decorrer, pelo menos em parte, da menor preferência dos cidadãos por esse serviço, como apontado anteriormente. Ou seja, mesmo mais próximos e, consequentemente, com maior possibilidade de organização, os indivíduos podem não pressionar, de forma incisiva, os governantes a investirem em rede coletora de esgoto. O porte do município (população) apresenta, nos três serviços, uma relação negativa e significativa com o déficit de acesso. Tomando por base a literatura, esse resultado era o esperado e pode sinalizar a existência de economias de escala e maior viabilidade econômica da provisão em função do número de potenciais contribuintes.

Analisando as variáveis educacionais, observa-se que os anos médios de estudo da população dos municípios só impactam negativa e significativamente o déficit de acesso a coleta de lixo. Taxa de analfabetismo apresenta uma relação positiva e significativa com o déficit de acesso a coleta de esgoto. No caso do abastecimento de água, a relação também é positiva, mas não apresenta significância estatística. De uma maneira geral, esses resultados não eram esperados.

Conforme apontado anteriormente, as variáveis razão de desigualdade e não branco, que representam, respectivamente, a desigualdade de renda e a heterogeneidade étnica do município, poderiam influenciar a distribuição mais equitativa do poder político e, consequentemente, a possibilidade de pressão, por parte daqueles que sofrem relativamente mais com o custo da degradação, para a adoção de medidas preservacionistas, inclusive a oferta de serviços adequados de saneamento ambiental. Apenas os coeficientes estimados da primeira variável são, nos três serviços, positivos e significativos, ou seja, quanto maior a desigualdade, maior o déficit. Isso pode ser reflexo, também, da possível baixa viabilidade econômica da provisão. 
As variáveis abaixo de 18 anos e acima de 65 anos foram incluídas com o intuito de capturar o impacto de características distintas da demanda, assim como dos estágios de consolidação dos municípios. A primeira variável apresenta significância estatística apenas no caso da coleta de esgoto, e a segunda, nesse serviço e na coleta de lixo (relações positivas). A variável área, por sua vez, que tenta capturar o efeito do desmembramento de municípios, apresenta relação positiva e significativa com os déficits de acesso a coleta de lixo e esgoto, mas negativa e significativa no caso do abastecimento de água.

A Tabela 5 apresenta os resultados das estimações das especificações de I a III para a variável dependente déficit no $1^{\circ}$ quintil. Nos casos da coleta de lixo e do abastecimento de água, observa-se, em todas as especificações, a existência de uma relação do tipo da CAK no formato de um " $\mathrm{N}$ " - coeficientes do polinômio de terceiro grau em relação à medida de desenvolvimento econômico (renda per capita) são significativos e apresentam os sinais esperados. No caso da coleta de esgoto, a especificação I mostra a existência de uma relação no tradicional formato de um "U invertido". Contudo, a inclusão de controles (especificação II) torna os coeficientes do polinômio não significativos, o que também se observa desconsiderando os municípios que privatizaram o serviço no período (especificação III).

Tabela 5

Resultados das estimações das especificações de I a III: variável dependente déficit no $1^{\circ}$ quintil

\begin{tabular}{|c|c|c|c|c|c|c|c|c|}
\hline \multirow{3}{*}{$\begin{array}{c}\text { Variáveis / } \\
\text { Especificações }\end{array}$} & \multicolumn{8}{|c|}{ Déficit no $1^{\circ}$ Quintil } \\
\hline & \multicolumn{2}{|c|}{ Lixo } & \multicolumn{3}{|c|}{ Esgoto } & \multicolumn{3}{|c|}{ Água } \\
\hline & $\mathrm{I}$ & II & $\mathrm{I}$ & II & III & $\mathrm{I}$ & II & III \\
\hline $\begin{array}{l}\text { Renda Municipal } \\
\text { per capita }\end{array}$ & $\begin{array}{l}5,299^{(a)} \\
(0,465)\end{array}$ & $\begin{array}{l}3,145^{(a)} \\
(0,468)\end{array}$ & $\begin{array}{l}1,064^{(\mathrm{b})} \\
(0,471)\end{array}$ & $\begin{array}{l}-0,706 \\
(0,490)\end{array}$ & $\begin{array}{l}-0,509 \\
(0,503)\end{array}$ & $\begin{array}{l}2,073^{(a)} \\
(0,444)\end{array}$ & $\begin{array}{l}1,137^{(\mathrm{b})} \\
(0,481)\end{array}$ & $\begin{array}{l}0,977^{(\mathrm{b})} \\
(0,492)\end{array}$ \\
\hline $\begin{array}{l}\text { Renda Municipal } \\
\text { per capita }^{2}\end{array}$ & $\begin{array}{l}-1,004^{(\mathrm{a})} \\
(0,098)\end{array}$ & $\begin{array}{l}-0,629^{(a)} \\
(0,098)\end{array}$ & $\begin{array}{l}-0,185^{(\mathrm{c})} \\
(0,099)\end{array}$ & $\begin{array}{c}0,138 \\
(0,102)\end{array}$ & $\begin{array}{c}0,096 \\
(0,104)\end{array}$ & $\begin{array}{l}-0,441^{(\mathrm{a})} \\
(0,093)\end{array}$ & $\begin{array}{l}-0,244^{(\mathrm{b})} \\
(0,099)\end{array}$ & $\begin{array}{l}-0,212^{(b)} \\
(0,101)\end{array}$ \\
\hline $\begin{array}{l}\text { Renda Municipal } \\
\text { per capita }^{3}\end{array}$ & $\begin{array}{l}0,061^{(\mathrm{a})} \\
(0,007)\end{array}$ & $\begin{array}{l}0,040^{(\mathrm{a})} \\
(0,007)\end{array}$ & $\begin{array}{c}0,010 \\
(0,007)\end{array}$ & $\begin{array}{l}-0,008 \\
(0,007)\end{array}$ & $\begin{array}{l}-0,005 \\
(0,007)\end{array}$ & $\begin{array}{l}0,030^{(a)} \\
(0,006)\end{array}$ & $\begin{array}{l}0,016^{(\mathrm{b})} \\
(0,007)\end{array}$ & $\begin{array}{l}0,014^{(\mathrm{b})} \\
(0,007)\end{array}$ \\
\hline Dummy Ano & $\begin{array}{l}-0,178^{(a)} \\
(0,005)\end{array}$ & $\begin{array}{l}-0,198^{(a)} \\
(0,018)\end{array}$ & $\begin{array}{l}-0,122^{(a)} \\
(0,005)\end{array}$ & $\begin{array}{l}-0,123^{(a)} \\
(0,016)\end{array}$ & $\begin{array}{l}-0,122^{(a)} \\
(0,017)\end{array}$ & $\begin{array}{l}-0,133^{(a)} \\
(0,005)\end{array}$ & $\begin{array}{l}-0,080^{(\mathrm{a})} \\
(0,018)\end{array}$ & $\begin{array}{l}-0,087^{(a)} \\
(0,017)\end{array}$ \\
\hline Controles & Não & Sim & Não & Sim & Sim & Não & Sim & Sim \\
\hline Observações & 9.680 & 9.642 & 9.963 & 9.925 & 9.818 & 9.981 & 9.943 & 9.821 \\
\hline Grupos & 5.500 & 5.483 & 5.483 & 5.466 & 5.436 & 5.500 & 5.483 & 5.447 \\
\hline Prob $>F$ & 0,000 & 0,000 & 0,000 & 0,000 & 0,000 & 0,000 & 0,000 & 0,000 \\
\hline $\begin{array}{l}\text { Teste de } \\
\text { Hausman }\end{array}$ & $268,6^{(a)}$ & $525,6^{(\mathrm{a})}$ & $283,4^{(\mathrm{a})}$ & $73,8^{(\mathrm{a})}$ & $82,96^{(\mathrm{a})}$ & $159,5^{(\mathrm{a})}$ & $248,7^{(\mathrm{a})}$ & $270,4^{(\mathrm{a})}$ \\
\hline
\end{tabular}

Obs.: erros-padrão entre parênteses. ${ }^{(a)}$ Significativo a $1 \% .{ }^{(b)}$ Significativo a 5\%. ${ }^{\text {(c) }}$ Significativo a $10 \%$. 
Na Tabela 6, são apresentados os resultados das estimações das especificações de I a III para a variável dependente déficit no $5^{\circ}$ quintil. Nos casos da coleta de lixo e da coleta de esgoto, observa-se, em todas as especificações, a existência de uma relação entre os déficits de acesso e o desenvolvimento econômico no formato de um "N", uma vez que os coeficientes do polinômio de terceiro grau em relação à renda per capita são significativos e apresentam os sinais esperados. No abastecimento de água, a especificação I mostra a existência de uma relação no formato de um "N invertido", ou seja, o déficit entre os domicílios mais ricos diminui em estágios iniciais de desenvolvimento, passa a aumentar a partir de certo estágio, mas volta a cair. A relação não assume, portanto, nenhum dos dois formatos considerados da CAK. Ainda no caso da água, a inclusão de controles (especificação II) torna os coeficientes do polinômio não significativos, o que também se observa desconsiderando os municípios que privatizaram o serviço no período (especificação III).

Tabela 6

Resultados das estimações das especificações de I a III: variável dependente déficit no $5^{\circ}$ quintil

\begin{tabular}{|c|c|c|c|c|c|c|c|c|}
\hline \multirow{3}{*}{$\begin{array}{c}\text { Variáveis / } \\
\text { Especificações }\end{array}$} & \multicolumn{8}{|c|}{ Déficit no $5^{\circ}$ Quintil } \\
\hline & \multicolumn{2}{|c|}{ Lixo } & \multicolumn{3}{|c|}{ Esgoto } & \multicolumn{3}{|c|}{ Água } \\
\hline & $\mathrm{I}$ & II & I & II & III & $\mathrm{I}$ & II & III \\
\hline $\begin{array}{l}\text { Renda Municipal } \\
\text { per capita }\end{array}$ & $\begin{array}{l}2,908^{(\mathrm{a})} \\
(0,551)\end{array}$ & $\begin{array}{l}4,864^{(\mathrm{a})} \\
(0,569)\end{array}$ & $\begin{array}{l}1,954^{(a)} \\
(0,556)\end{array}$ & $\begin{array}{l}1,585^{(a)} \\
(0,607)\end{array}$ & $\begin{array}{l}1,881^{(a)} \\
(0,621)\end{array}$ & $\begin{array}{l}-2,527^{(a)} \\
(0,497)\end{array}$ & $\begin{array}{l}-0,090 \\
(0,511)\end{array}$ & $\begin{array}{l}-0,259 \\
(0,519)\end{array}$ \\
\hline $\begin{array}{l}\text { Renda Municipal } \\
\text { per capita }\end{array}$ & $\begin{array}{l}-0,739^{(a)} \\
(0,116)\end{array}$ & $\begin{array}{l}-1,070^{(a)} \\
(0,118)\end{array}$ & $\begin{array}{l}-0,464^{(a)} \\
(0,115)\end{array}$ & $\begin{array}{l}-0,388^{(a)} \\
(0,124)\end{array}$ & $\begin{array}{l}-0,451^{(a)} \\
(0,127)\end{array}$ & $\begin{array}{l}0,402^{(\mathrm{a})} \\
(0,102)\end{array}$ & $\begin{array}{c}0,013 \\
(0,103)\end{array}$ & $\begin{array}{c}0,050 \\
(0,105)\end{array}$ \\
\hline $\begin{array}{l}\text { Renda Municipal } \\
\text { per capita }{ }^{3}\end{array}$ & $\begin{array}{l}0,059^{(a)} \\
(0,008)\end{array}$ & $\begin{array}{l}0,077^{(a)} \\
(0,008)\end{array}$ & $\begin{array}{l}0,035^{(a)} \\
(0,008)\end{array}$ & $\begin{array}{l}0,030^{(a)} \\
(0,008)\end{array}$ & $\begin{array}{l}0,035^{(a)} \\
(0,009)\end{array}$ & $\begin{array}{l}-0,019^{(a)} \\
(0,007)\end{array}$ & $\begin{array}{c}0,000 \\
(0,007)\end{array}$ & $\begin{array}{l}-0,003 \\
(0,007)\end{array}$ \\
\hline Dummy Ano & $\begin{array}{l}-0,172^{(a)} \\
(0,005)\end{array}$ & $\begin{array}{l}-0,090^{(a)} \\
(0,019)\end{array}$ & $\begin{array}{l}-0,126^{(\mathrm{a})} \\
(0,005)\end{array}$ & $\begin{array}{l}-0,134^{(\mathrm{a})} \\
(0,019)\end{array}$ & $\begin{array}{l}-0,133^{(a)} \\
(0,019)\end{array}$ & $\begin{array}{l}-0,145^{(\mathrm{a})} \\
(0,006)\end{array}$ & $\begin{array}{l}-0,032^{(\mathrm{c})} \\
(0,018)\end{array}$ & $\begin{array}{c}-0,037^{(b)} \\
(0,018)\end{array}$ \\
\hline Controles & Não & Sim & Não & Sim & Sim & Não & Sim & Sim \\
\hline Observações & 9.680 & 9.642 & 9.980 & 9.942 & 9.833 & 9.981 & 9.943 & 9.821 \\
\hline Grupos & 5.500 & 5.483 & 5.499 & 5.482 & 5.450 & 5.500 & 5.483 & 5.447 \\
\hline Prob $>\mathrm{F}$ & 0,000 & 0,000 & 0,000 & 0,000 & 0,000 & 0,000 & 0,000 & 0,000 \\
\hline Teste de Hausman & $601,9^{(a)}$ & $300,5^{(\mathrm{a})}$ & $428,1^{(a)}$ & $621,0^{(a)}$ & $525,7^{(a)}$ & $381,1^{(\mathrm{a})}$ & $256,0^{(a)}$ & $246,6^{(a)}$ \\
\hline
\end{tabular}

Obs.: erros-padrão entre parênteses. ${ }^{(a)}$ Significativo a $1 \% .{ }^{(b)}$ Significativo a $5 \% .{ }^{(c)}$ Significativo a $10 \%$.

A Tabela 7, por sua vez, apresenta os resultados das estimações (especificação II) que consideram, como variáveis dependentes, os indicadores de déficit de acesso urbano (total, $1^{\circ}$ e $5^{\circ}$ quintis). Observa-se que, apenas no abastecimento de água, o déficit de acesso urbano total não indica uma relação no formato de um "N" com a renda per capita. Nesse caso, a relação seria no formato de um "N invertido". Além disso, deve-se destacar que, em nenhum quintil de rendimento domiciliar, nos três serviços, o déficit de acesso urbano apresentou uma relação no formato tradicional da CAK ("U invertido") ou no formato de um "N". 
Déficit de acesso a serviços de saneamento ambiental: evidências de uma Curva Ambiental de Kuznets...

Tabela 7

Resultados das estimações da especificação II: variável dependente déficit urbano (total, $1^{\circ}$ e $5^{\circ}$ quintis)

\begin{tabular}{|c|c|c|c|c|c|c|c|c|c|}
\hline \multirow{3}{*}{$\begin{array}{c}\text { Variáveis / } \\
\text { Especificações }\end{array}$} & \multicolumn{9}{|c|}{ Déficit Urbano } \\
\hline & \multicolumn{3}{|c|}{ Lixo } & \multicolumn{3}{|c|}{ Esgoto } & \multicolumn{3}{|c|}{ Água } \\
\hline & Total & $1^{\circ}$ Quintil & $5^{\circ}$ Quintil & Total & $1^{\circ}$ Quintil & $5^{\circ}$ Quintil & Total & $1^{\circ}$ Quintil & $5^{\circ}$ Quintil \\
\hline $\begin{array}{l}\text { Renda Municipal } \\
\text { per capita }\end{array}$ & $\begin{array}{l}6,800^{(a)} \\
(0,717)\end{array}$ & $\begin{array}{c}0,036 \\
(0,030)\end{array}$ & $\begin{array}{c}-2,385^{(a)} \\
(0,415)\end{array}$ & $\begin{array}{l}1,269^{(\mathrm{c})} \\
(0,706)\end{array}$ & $\begin{array}{c}-0,030^{(\mathrm{c})} \\
(0,015)\end{array}$ & $\begin{array}{c}0,013 \\
(0,008)\end{array}$ & $\begin{array}{l}-1,636^{(b)} \\
(0,753)\end{array}$ & $\begin{array}{c}0,000 \\
(0,039)\end{array}$ & $\begin{array}{l}0,052^{(\mathrm{c})} \\
(0,031)\end{array}$ \\
\hline $\begin{array}{l}\text { Renda Municipal } \\
\text { per capita }^{2}\end{array}$ & $\begin{array}{c}-1,438^{(a)} \\
(0,146)\end{array}$ & $\begin{array}{l}-0,006 \\
(0,006)\end{array}$ & $\begin{array}{l}0,528^{(a)} \\
(0,084)\end{array}$ & $\begin{array}{c}-0,310^{(\mathrm{b})} \\
(0,144)\end{array}$ & $\begin{array}{l}0,006^{(\mathrm{b})} \\
(0,003)\end{array}$ & $\begin{array}{l}-0,003 \\
(0,002)\end{array}$ & $\begin{array}{l}0,332^{(\mathrm{b})} \\
(0,151)\end{array}$ & $\begin{array}{c}0,001 \\
(0,008)\end{array}$ & $\begin{array}{l}-0,009 \\
(0,006)\end{array}$ \\
\hline $\begin{array}{l}\text { Renda Municipal } \\
\text { per capita }^{3}\end{array}$ & $\begin{array}{l}0,099^{(a)} \\
(0,010)\end{array}$ & $\begin{array}{c}0,000 \\
(0,000)\end{array}$ & $\begin{array}{l}-0,038^{(a)} \\
(0,006)\end{array}$ & $\begin{array}{l}0,024^{(\mathrm{b})} \\
(0,010)\end{array}$ & $\begin{array}{c}0,000 \\
(0,000)\end{array}$ & $\begin{array}{c}0,000 \\
(0,000)\end{array}$ & $\begin{array}{l}-0,022^{(b)} \\
(0,010)\end{array}$ & $\begin{array}{c}0,000 \\
(0,001)\end{array}$ & $\begin{array}{c}0,001 \\
(0,000)\end{array}$ \\
\hline Dummy Ano & $\begin{array}{l}-0,149^{(a)} \\
(0,024)\end{array}$ & $\begin{array}{c}0,002 \\
(0,001)\end{array}$ & $\begin{array}{l}0,074^{(a)} \\
(0,012)\end{array}$ & $\begin{array}{l}-0,127^{(\mathrm{a})} \\
(0,023)\end{array}$ & $\begin{array}{l}-0,001 \\
(0,001)\end{array}$ & $\begin{array}{c}0,000 \\
(0,000)\end{array}$ & $\begin{array}{l}0,041^{(\mathrm{c})} \\
(0,024)\end{array}$ & $\begin{array}{c}0,001 \\
(0,001)\end{array}$ & $\begin{array}{l}-0,001 \\
(0,001)\end{array}$ \\
\hline Controles & Sim & Sim & Sim & Sim & Sim & Sim & Sim & Sim & Sim \\
\hline Observ & 9.642 & 9.642 & 9.642 & 9.943 & 9.943 & 9.943 & 9.943 & 9.943 & 9.943 \\
\hline Grupos & 5.483 & 5.483 & 5.483 & 5.483 & 5.483 & 5.483 & 5.483 & 5.483 & 5.483 \\
\hline Prob $>$ F & 0,000 & 0,000 & 9.642 & 0,000 & 0,000 & 0,000 & 0,000 & 0,000 & 0,000 \\
\hline $\begin{array}{l}\text { Teste de } \\
\text { Hausman }\end{array}$ & $185,8^{(a)}$ & $813,7^{(\mathrm{b})}$ & $743,3^{(a)}$ & $569,4^{(a)}$ & $161,7^{(\mathrm{c})}$ & $31,3^{(\mathrm{c})}$ & $216,7^{(a)}$ & $205,4^{(\mathrm{c})}$ & $83,9^{(c)}$ \\
\hline
\end{tabular}

Obs.: erros-padrão entre parênteses. ${ }^{\text {(a) }}$ Significativo a $1 \%$. ${ }^{\text {(b) }}$ Significativo a $5 \%$. ${ }^{\text {(c) }}$ Significativo a $10 \%$.

Já na Tabela 8, são apresentados os resultados das estimações da especificação IV para os três serviços e os três indicadores de déficit de acesso. Essa especificação desagrega a amostra em regiões geográficas. Analisando o déficit total, observa-se que, no caso da coleta de lixo, apenas na Região CentroOeste, não se verifica uma relação do tipo da CAK no formato de um "N" - nessa região, os coeficientes do polinômio de terceiro grau em relação à medida de desenvolvimento econômico não são significativos. No caso da coleta de esgoto, as regiões Norte e Centro-Oeste não apresentam uma CAK nem no formato de um " $U$ invertido", nem no de um "N" - coeficientes não significativos. No caso do abastecimento de água, apenas os coeficientes do polinômio de terceiro grau das regiões Nordeste e Sudeste são significativos, representando uma relação no formato de um "N".

Analisando o déficit no $1^{\circ}$ quintil, verifica-se que, no caso da coleta de lixo, as regiões Norte e Centro-Oeste são as que apresentam coeficientes não significativos do polinômio; nas demais, a CAK assume o formato de um "N". Em relação ao esgoto, as regiões Nordeste e Sudeste apresentam uma CAK no formato de um "N"; no Norte, os coeficientes não são significativos. No Centro-Oeste e no Sul, a relação entre déficit de acesso e renda per capita assume o formato de um "N invertido". No que diz respeito ao abastecimento de água, apenas o Nordeste e o Sudeste apresentam relações significativas, no formato de um "N". 
Tabela 8

Resultados das estimações da especificação IV: variáveis dependentes déficit no total, déficit no $1^{\circ}$ quintil e déficit no $5^{\circ}$ quintil

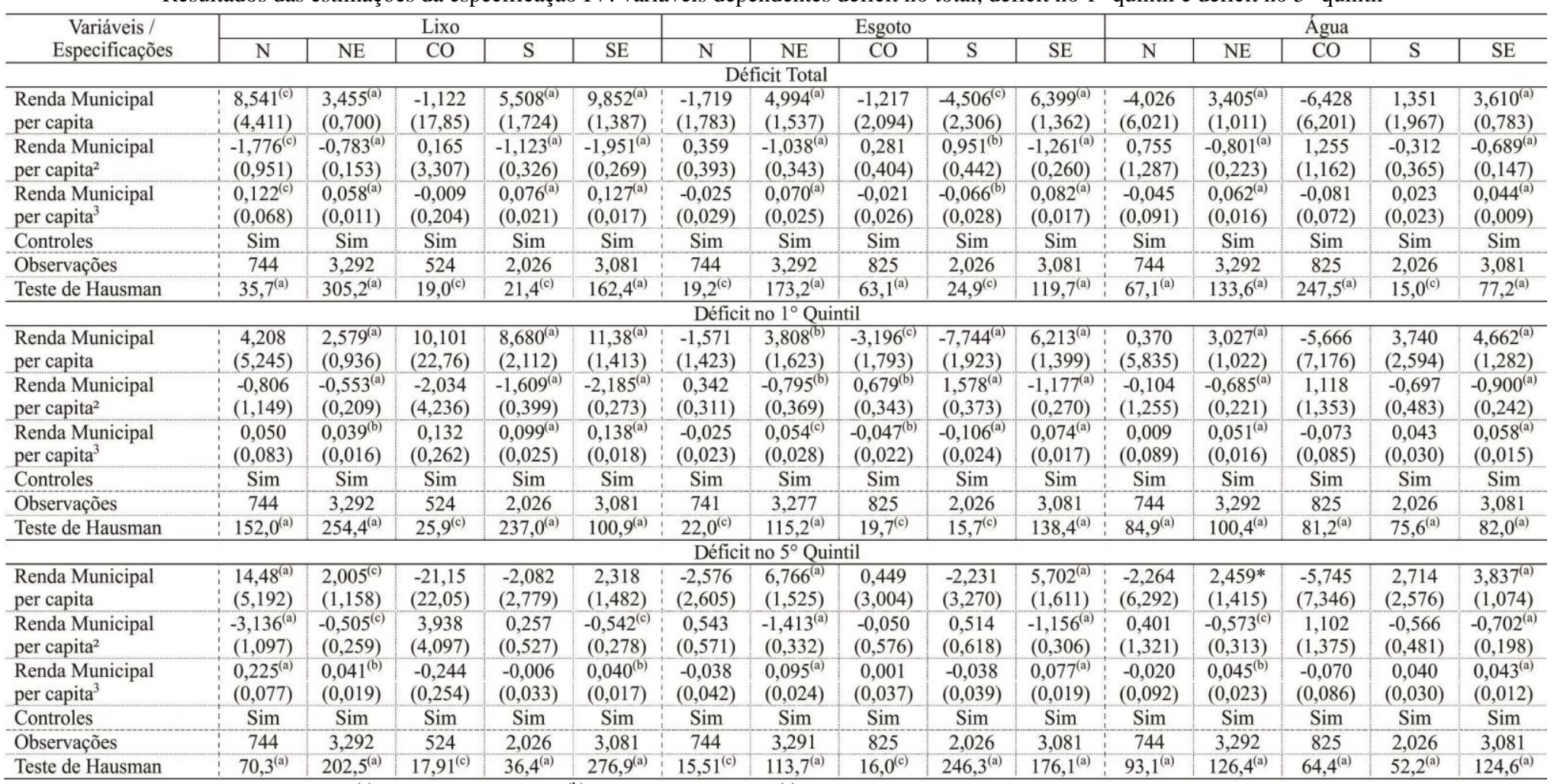

Obs.: erros-padrão entre parênteses. ${ }^{\text {(a) }}$ Significativo a $1 \% .{ }^{(\mathrm{b})}$ Significativo a $5 \% .{ }^{\left({ }^{c}\right)}$ Significativo a $10 \%$. 
Avaliando o déficit no $5^{\circ}$ quintil, observa-se que, no caso da coleta de lixo, apenas as regiões Norte e Nordeste apresentam relações no formato de um "N"; nas demais regiões, de uma maneira geral, os coeficientes são não significativos. Os resultados da coleta de esgoto indicam que apenas as regiões Nordeste e Sudeste apresentam uma CAK também no formato de um "N". No abastecimento de água, a relação também só se verifica nessas regiões.

É importante destacar que a Tabela 3, analisada anteriormente, mostra que os indicadores de déficit de acesso, em todas as regiões, se correlacionam negativamente à renda per capita. No entanto, os resultados das estimações na tabela 8 sinalizam que, em alguns casos, essas relações são positivas ou não significativas, o que sugere que não é o efeito renda que prevalece e influencia o acesso, mas sim outras variáveis referentes à renda. Além disso, para justificar as relações distintas entre o déficit de acesso e o desenvolvimento econômico obtidas em algumas regiões é necessário um estudo mais detalhado que diferencie os municípios de cada uma delas em relação a algumas características, como portes (populações), densidades demográficas, urbanizações, entre outras.

\section{Considerações finais}

O presente estudo avaliou a existência de uma Curva Ambiental de Kuznets (CAK) para o caso dos déficits municipais de acesso a serviços de saneamento ambiental, que podem ser considerados como medidas indiretas de degradação ambiental. De acordo com essa hipótese, existiria uma relação não linear, no formato de um "U invertido" entre indicadores de degradação e o desenvolvimento econômico, ou seja, nos primeiros estágios do desenvolvimento, a degradação aumentaria, mas passaria a diminuir em estágios mais avançados. Tal hipótese justifica a afirmação de Beckerman (1992) de que o desenvolvimento econômico possui impactos iniciais negativos sobre o meio ambiente, mas que, ao longo do tempo, seria a melhor forma de gerar uma maior preservação. Contudo, em estudos mais recentes, foi constatado que, para alguns indicadores, a queda da degradação não se sustentaria ao longo do tempo, de modo que a CAK teria, na verdade, o formato de um "N".

Nas estimações realizadas, foram avaliados três serviços de saneamento ambiental (coleta de lixo, coleta de esgoto e abastecimento de água) e três indicadores municipais de déficit de acesso: um que considera a proporção total de domicílios sem acesso (déficit total), um que considera a proporção dos domicílios mais pobres sem acesso (déficit no $1^{\circ}$ quintil) e outro que considera a proporção dos domicílios mais ricos sem acesso (déficit no $5^{\circ}$ quintil). Além disso, baseandose nas revisões da literatura e nas análises descritivas realizadas nas primeiras seções, foram utilizadas variáveis de controle que influenciariam tanto o acesso 
como a degradação ambiental com o objetivo de averiguar se as evidências obtidas refletem outras diferenças entre os municípios e não a CAK.

Para testar a robustez dos resultados, também foram realizadas estimações retirando da amostra os municípios que, no período, concederam os serviços à iniciativa privada. Ou seja, foram desconsiderados os potenciais efeitos da privatização sobre os resultados. Além disso, testou-se a existência da relação CAK , considerando indicadores de déficit de acesso urbano. Outro teste de robustez foi a desagregação da amostra em regiões geográficas com o objetivo de avaliar se os resultados encontrados refletem diferenças regionais entre os municípios e não apenas a relação entre degradação ambiental e desenvolvimento econômico.

Os resultados obtidos para a amostra completa e para o déficit total sinalizam, de uma maneira geral, a existência de uma relação entre a degradação ambiental e o desenvolvimento econômico no formato de um " $\mathrm{N}$ ". Ou seja, a CAK não assume o formato tradicional de um "U invertido". Portanto, para o caso específico dos serviços de saneamento ambiental nos municípios brasileiros, a afirmação de Beckerman (1992) não é verdadeira, uma vez que, ao longo do tempo, o desenvolvimento econômico voltaria a gerar degradação ambiental.

Deve-se destacar que, ao considerar indicadores de déficit de acesso de acordo com o perfil da renda dos domicílios, ao levar em conta apenas informações de domicílios urbanos e ao desagregar a amostra por regiões geográficas, não foram encontradas, de uma maneira geral, relações do tipo da CAK, nem no formato de um "U invertido", nem no formato de um "N". Assim, os resultados para a amostra completa de municípios e para os déficits totais também podem refletir diferenças de preferências e de capacidade de pagamento dos cidadãos, características regionais, motivações distintas dos políticos e diferentes direcionamentos de recursos para a realização de investimentos no setor.

As evidências encontradas mostram, portanto, que o acesso a serviços de saneamento ambiental é influenciado por um conjunto amplo de fatores e não apenas pela renda. Assim, não se pode esperar que o próprio desenvolvimento econômico seja a solução para o problema, o que os resultados das estimações realizadas mostraram ao apontar relações diferentes do tradicional "U invertido" da CAK. Uma possível solução seria a participação mais efetiva do governo federal nos serviços, direcionando recursos para a realização de investimentos que atendam a população dos locais menos desenvolvidos, mas também garantindo que a população com menor renda das localidades mais desenvolvidas também seja atendida. As concentrações de pessoas de baixa renda em municípios desenvolvidos pode ser uma das explicações da reversão da queda do déficit.

O presente estudo foi um primeiro esforço para apontar evidências da dinâmica dos déficits de acesso a serviços de saneamento ambiental ao longo do 
desenvolvimento econômico dos municípios brasileiros, fugindo do escopo uma explicação mais pormenorizada dos motivos que levam aos padrões distintos encontrados entre os serviços, as regiões, as áreas (urbanas e rurais) e os perfis de renda domiciliar - apesar de algumas possíveis justificativas terem sido apontadas ao longo do estudo. Essa pode ser uma agenda de pesquisa para trabalhos futuros.

\section{Referências bibliográficas}

ANDREONI, J.; LEVINSON, A. The simple analytics of the environmental Kuznets curve. Journal of Public Economics, n. 80, p. 269-286, 2001.

ARRAES, R. A. et al.. Curva ambiental de Kuznets e desenvolvimento sustentável. Revista de Economia e Sociologia Rural, Rio de Janeiro, v. 44, n. 3, p. 525-547, jul./set. 2006.

ARROW, K. et al.. Economic growth, carrying capacity, and the environment. Science, n. 268, p. 520-521, 1995.

BARAT, J. O financiamento da infra-estrutura urbana: os impasses, as perspectivas institucionais, as perspectivas financeiras, In: IPEA. Infra-estrutura: perspectivas de reorganização (financiamento). Brasília, 1998.

BECKERMAN, W. Economic growth and the environment: whose growth? Whose environment?. World Development, v. 20, n. 4, p. 481-496, 1992.

BICHIR, R. Determinantes do acesso à infra-estrutura urbana no município de São Paulo. Revista Brasileira de Ciências Sociais, 2009.

BNDES. Saneamento: o objetivo é a eficiência. Informes Infra-Estrutura do BNDES, n. 23, jun. 1998.

DEUTSCH, J.; SILBER, J. The Kuznets curve and the impact of various income sources on the link between inequality and development. Working Paper Bar-Ilan University, 2000.

DINDA, S. Environmental Kuznets curve hypothesis: a survey. Ecological Economics, n. 49, p. 431-455, 2004.

FIELDS, G. S.; JAKUBSON, G. H. New evidence on the Kuznets Curve. Working Paper Cornell University, 1994.

FONSECA, L. N.; RIBEIRO, E. P. Preservação ambiental e crescimento econômico no Brasil. In: ENCONTRO DE ECONOMIA DA REGIÃO SUL, 8, Anais... Anpec, 2005.

GALIANI, S. et al. Water for life: the impact of the privatization of water services on child mortality. Journal of Political Economy, v. 113, n. 1, 2005.

GRADSTEIN, M.; JUSTMAN, M. The democratization of political elites and the decline in inequality in modern economic growth. In: BREZIS, E.; TEMIN, P. (Ed.). Elites, minorities, and economic growth. Amsterdam: Elsevier, 1999.

GROSSMAN, G. M.; KRUEGER, A. B. Environmental impacts of the North American free trade agreement. NBER, 1991. (Working Paper, n. 3914).

JONES, L. E.; MANUELLI, R. E. A positive model of growth and pollution controls. Working Paper of National Bureau of Economic Research, n. 5205, Cambridge, 1998. 
KUZNETS, S. Economic growth and income inequality. American Economic Review, v. 45, n.1, p.1-28, 1955.

MARQUES, E. Estado e redes sociais: permeabilidade e coesão nas políticas urbanas no Rio de Janeiro. Revan/Fapesp, 2000.

MEJIA, A. et al. Água, redução de pobreza e desenvolvimento sustentável. Série Água Brasil (Banco Mundial), Brasília, n. 4, jun. 2003.

MENDONÇA, M. J. C. et al. Demanda por saneamento no Brasil: uma aplicação do modelo logit multinomial. Economia Aplicada, v. 8, n. 1, p. 143-163, 2004.

; MOTTA, R. S. Saúde e saneamento no Brasil. Ipea, 2005. (Textos para Discussão, n. 1081).

MOREIRA, T. Saneamento básico: desafios e oportunidades. Revista do BNDES, 1996.

MOTTA, R. S. Questões regulatórias do setor de saneamento no Brasil. Notas Técnicas do IPEA, 2004.

REZENDE, S. et al.. Integrando oferta e demanda de serviços de saneamento: análise hierárquica do panorama urbano brasileiro no ano 2000. Revista de Engenharia Sanitária Ambiental, 2007.

SAIANI, C. C. S. Déficit de acesso aos serviços de saneamento básico no Brasil. Prêmio Ipea-Caixa 2006. Brasília, 2006.

SANTOS, R. B. N. et al. Estimativa da Curva de Kuznets Ambiental para a Amazônia Legal. In: CONGRESSO DA SOCIEDADE BRASILEIRA DE ECONOMIA, ADMINISTRAÇÃO E SOCIOLOGIA RURAL, 46, 2008. Anais...

SELDEN, T. M.; SONG, D. Environmental quality and development: is there a Kuznets curve for air pollution emission? Journal of Environmental Economics and Management, v. 27, p. 147-162, 1994.

SHAFIK, N.; BANDYOPADHYAY, S. Economic growth and environmental quality: time series and cross-country evidence. World Development Report, World Bank, Washington, DC, 1992.

SOUSA, A. G. N. et al. Sustentabilidade e meio ambiente no Brasil: uma análise a partir da Curva de Kuznets. In: CONGRESSO DA SOCIEDADE BRASILEIRA DE ECONOMIA, ADMINISTRAÇÃO E SOCIOLOGIA RURAL, 46, 2008. Anais...

STERN, D. I. The rise and fall of environmental Kuznets curve. World Development, v. 32, n. 8, p. 1419-1439, 2004.

TEMPLETON, S. R.; SCHERR, S. J. Effects of demographic and related microeconomic change on land quality in hills and mountains of developing countries. World Development, v. 27, n. 6, p. 903-918, 1999.

TONETO JÚNIOR, R.; SAIANI, C. C. S. Restrições à expansão dos investimentos no saneamento básico brasileiro. Revista Econômica do Nordeste, 2006.

TORRAS, M.; BOYCE, J. K. Income, inequality and pollution: a reassessment of the environmental Kuznets curve. Ecological Economics, n. 25, p. 147-160, 1998.

YANDLE, B. et al.. The environmental Kuznets curve: a primer. PERC Research Study, n. 02-1, May 2002. 
Déficit de acesso a serviços de saneamento ambiental: evidências de uma Curva Ambiental de Kuznets...

\section{Apêndice}

Tabela A.1

Brasil: correlações entre os indicadores municipais de desenvolvimento econômico, de concentração populacional, de porte e de educação, 1991 e 2000

\begin{tabular}{|c|c|c|c|c|c|}
\hline Indicadores Municipais & $\begin{array}{c}\text { Taxa de } \\
\text { Urbanização }\end{array}$ & $\begin{array}{c}\text { Densidade } \\
\text { Demográfica }\end{array}$ & População & $\begin{array}{l}\text { Anos de } \\
\text { Estudo }\end{array}$ & $\begin{array}{c}\text { Taxa de } \\
\text { Analfabetismo }\end{array}$ \\
\hline \multicolumn{6}{|c|}{1991} \\
\hline Renda per capita & $0,63^{(a)}$ & $0,25^{\text {(a) }}$ & $0,24^{(a)}$ & $0,86^{(\mathrm{a})}$ & $-0,77^{(a)}$ \\
\hline Taxa de Urbanização & & $0,23^{(a)}$ & $0,17^{(\mathrm{a})}$ & $0,66^{(\mathrm{a})}$ & $-0,50^{(a)}$ \\
\hline Densidade Demográfica & & & $0,43^{(\mathrm{a})}$ & $0,24^{(\mathrm{a})}$ & $-0,13^{(a)}$ \\
\hline População & & & & $0,21^{(\mathrm{a})}$ & $-0,10^{(a)}$ \\
\hline Anos de Estudo & & & & & $-0,91^{(\mathrm{a})}$ \\
\hline \multicolumn{6}{|c|}{2000} \\
\hline Renda per capita & $0,54^{(\mathrm{a})}$ & $0,23^{(a)}$ & $0,22^{(a)}$ & $0,88^{(\mathrm{a})}$ & $-0,81^{(\mathrm{a})}$ \\
\hline Taxa de Urbanização & & $0,22^{(a)}$ & $0,16^{(\mathrm{a})}$ & $0,65^{(\mathrm{a})}$ & $-0,45^{(a)}$ \\
\hline Densidade Demográfica & & & $0,45^{(\mathrm{a})}$ & $0,26^{(\mathrm{a})}$ & $-0,14^{(a)}$ \\
\hline População & & & & $0,21^{(\mathrm{a})}$ & $-0,10^{(\mathrm{a})}$ \\
\hline Anos de Estudo & & & & & $-0,89^{(a)}$ \\
\hline
\end{tabular}

${ }^{(a)}$ Significativo a $1 \% \cdot{ }^{(b)}$ Significativo a $5 \% \cdot{ }^{(c)}$ Significativo a $10 \%$.

Fonte: IBGE, Censos Demográficos de 1991 e 2000. Elaboração própria.

Tabela A.2

Estatísticas descritivas das variáveis de controle (1991 e 2000)

\begin{tabular}{|c|c|c|c|c|}
\hline Indicadores Municipais & Médias & Desvios-Padrão & Mínimos & Máximos \\
\hline \multicolumn{5}{|c|}{1991} \\
\hline Taxa de Urbanização & 0,54 & 0,23 & 0,03 & 1,00 \\
\hline Densidade Demográfica & 88,07 & 497,26 & 0,00 & $12.199,77$ \\
\hline População & $31.244,85$ & $186.737,90$ & 751,00 & $9.649 .519,00$ \\
\hline Anos de Estudo & 3,17 & 1,25 & 0,34 & 8,84 \\
\hline Taxa de Analfabetismo & 30,18 & 16,41 & 1,81 & 84,17 \\
\hline Razão de Desigualdade & 16,47 & 16,33 & 4,68 & 996,04 \\
\hline Não Branco & 0,50 & 0,28 & 0,00 & 1,00 \\
\hline Energia e Televisão & 52,27 & 26,56 & 1,56 & 97,51 \\
\hline Carro & 15,36 & 12,32 & 0,00 & 60,01 \\
\hline Telefone & 7,52 & 7,41 & 0,00 & 59,81 \\
\hline Geladeira & 48,46 & 28,19 & 0,51 & 98,63 \\
\hline Abaixo de 18 Anos & 0,46 & 0,06 & 0,28 & 0,65 \\
\hline Acima de 65 Anos & 0,05 & 0,02 & 0,00 & 0,13 \\
\hline Área & $1.899,69$ & $6.911,01$ & 3,70 & $166.278,50$ \\
\hline
\end{tabular}


Carlos César Santejo Saiani / Rudinei Toneto Junior / Juscelino Antonio Dourado

Continua...

Tabela A.2 - Continuação

\begin{tabular}{|c|c|c|c|c|}
\hline Indicadores Municipais & Médias & Desvios-Padrão & Mínimos & Máximos \\
\hline \multicolumn{5}{|c|}{2000} \\
\hline Taxa de Urbanização & 0,59 & 0,23 & 0,00 & 1,00 \\
\hline Densidade Demográfica & 98,21 & 534,44 & 0,13 & $12.915,98$ \\
\hline População & $30.904,37$ & $187.034,80$ & 795,00 & $10.400 .000,00$ \\
\hline Anos de Estudo & 4,04 & 1,29 & 0,81 & 9,65 \\
\hline Taxa de Analfabetismo & 21,78 & 12,47 & 0,91 & 60,66 \\
\hline Razão de Desigualdade & 24,58 & 57,59 & 4,33 & $2.631,83$ \\
\hline Não Branco & 0,47 & 0,26 & 0,00 & 0,99 \\
\hline Energia e Televisão & 75,00 & 20,37 & 6,24 & 99,54 \\
\hline Carro & 25,17 & 17,07 & 0,01 & 79,56 \\
\hline Telefone & 17,12 & 14,79 & 0,03 & 91,39 \\
\hline Geladeira & 68,59 & 24,74 & 4,70 & 99,73 \\
\hline Abaixo de 18 Anos & 0,38 & 0,06 & 0,22 & 0,61 \\
\hline Acima de 65 Anos & 0,06 & 0,02 & 0,01 & 0,16 \\
\hline Área & $1.546,01$ & $5.722,44$ & 2,90 & $160.755,00$ \\
\hline
\end{tabular}

Fonte: IBGE, Censos Demográficos de 1991 e 2000. Elaboração própria. 